\title{
A COMBINED ANALYTICAL AND EXPERIMENTAL APPROACH FOR PREDICTION OF PROPERTIES OF FUSED DEPOSITION MODELING (FDM) PARTS
}

A Dissertation

presented to

the Faculty of the Graduate School

at the University of Missouri-Columbia

In Partial Fulfillment

of the Requirements for the Degree

Doctor of Philosophy

by

THAO THI PHUONG PHAN

Dr. R. A. Winholtz, Dissertation Supervisor

DECEMBER 2020 
(C) Copyright by Thao Thi Phuong Phan 2020

\section{All Rights Reserved}


The undersigned, appointed by the dean of the Graduate School, have examined the dissertation entitled

\section{A COMBINED ANALYTICAL AND EXPERIMENTAL \\ APPROACH FOR PREDICTION OF PROPERTIES OF \\ FUSED DEPOSITION MODELING (FDM) PARTS \\ presented by Thao Thi Phuong Phan}

a candidate for the degree of Doctor of Philosophy,

and hereby certify that, in their opinion, it is worthy of acceptance.

Professor Robert Andy Winholtz

Professor Matt Maschmann

Professor Yuyi Lin

Professor Sanjeev Khanna

Professor Hani Salim 
To my beloved father, you inspired, disciplined and taught me all along the way. I would not be the person I am today without you. 


\section{ACKNOWLEDGEMENTS}

I would like to express the deepest appreciation to my supervisor, Professor R. A. Winholtz, who has the attitude and the substance of a genius: he has a spirit of adventure in regard to research and scholarship and an excitement in regard to teaching. Without his guidance and persistent help my work in this dissertation would not have been possible.

I would like to thank my committee members, Professor Matt Maschmann, Professor Yuyi Lin, Professor Sanjeev Khanna, and Professor Hani Salim, who have given me a lot of suggestions and graciously provided the time.

I would like to thank my former supervisor, Professor A. S. El-Gizawy, who gave me a research opportunity and brought me into his research team in my earlier steps of my doctoral program.

Last but not least, I would like to thank my beloved family, friends and everyone else who has accompanied me on my long walks. 


\section{Tables of contents}

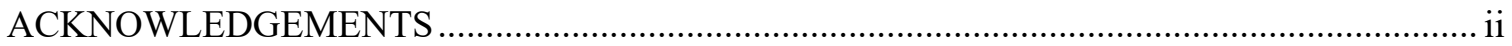

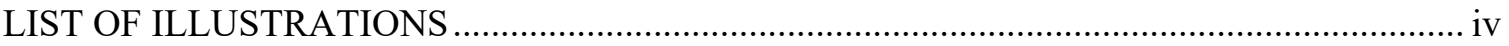

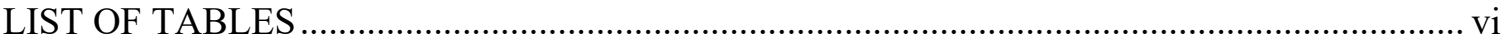

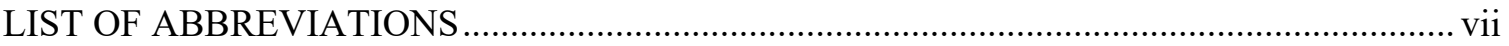

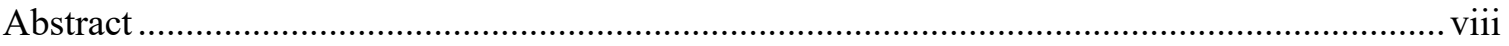

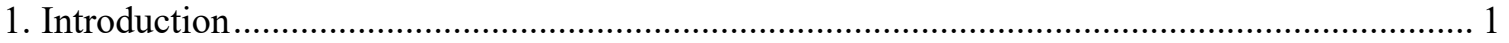

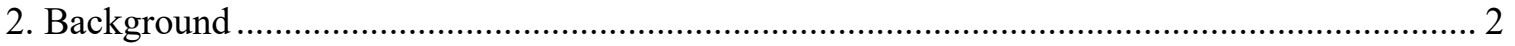

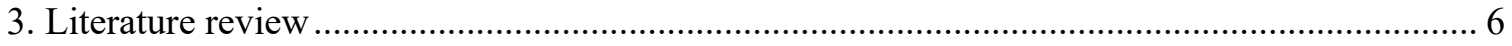

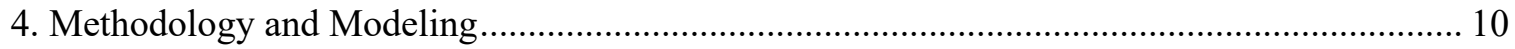

4.1. Experimental study of mechanical properties of FDM parts .............................................. 10

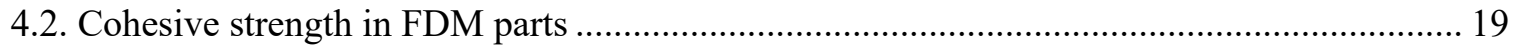

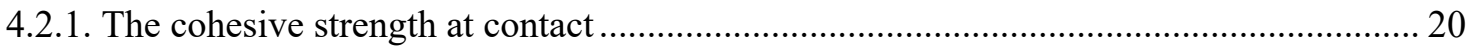

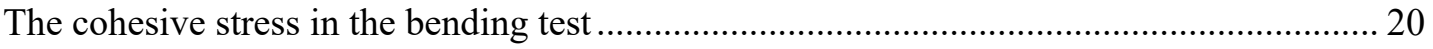

The second moment of inertia and its effective ratio for square contact areas ...................... 21

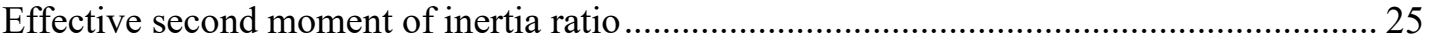

4.2.2. Determination of cohesive strength between layers at contact ..................................... 27

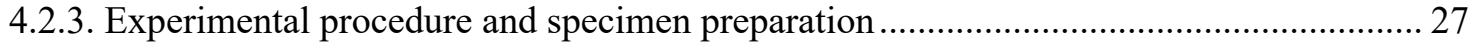

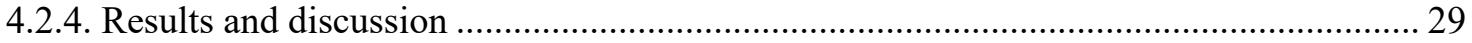

4.3. Modeling the effects of heat transfer on the true contact of adjacent rasters......................... 34

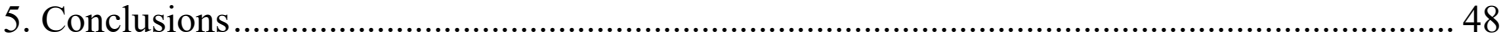

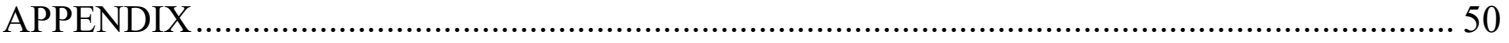

A. Calculation of cohesive strength between layers at contact................................................ 50

B.1. Temperature history of filament during printing process............................................... 51

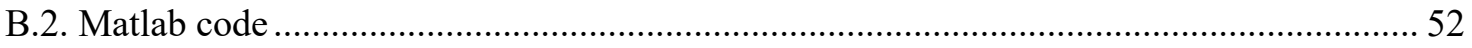

C. Parametric Study of FDM Process Design for ULTEM 9085 .......................................... 55

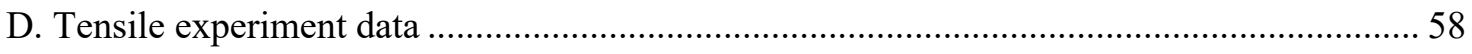

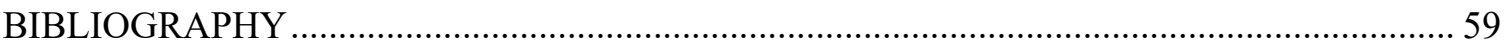

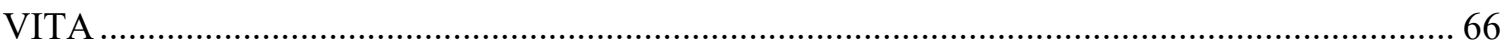




\section{LIST OF ILLUSTRATIONS}

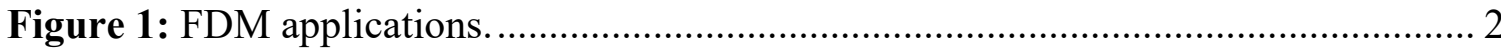

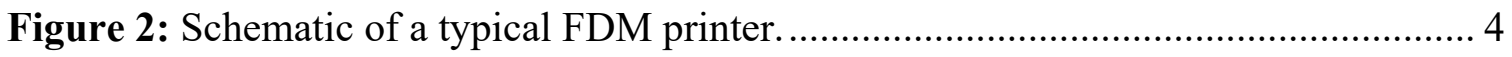

Figure 3: Working parameters of FDM process - ISO/ASTM52921 - 13 standards........ 4

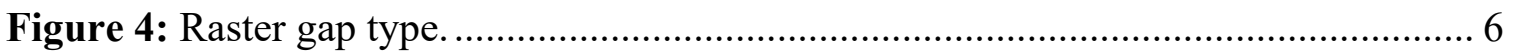

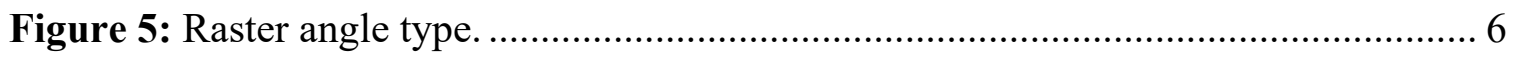

Figure 6: Cause and effect diagram of FDM process parameter.................................... 10

Figure 7: (a) Specimen for the tensile test and (b) bending test. ..................................... 12

Figure 8: Notches creates stress concentrations at layer edges. .................................... 15

Figure 9: Fracture surface of the bending specimens (a) $0.0025 \mathrm{~mm},\left[+30^{\circ},-60^{\circ}\right]$; (b) -

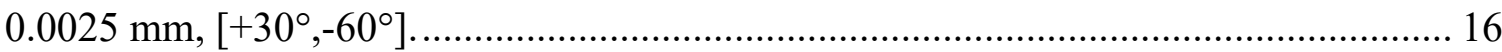

Figure 10: Fracture surface of the tensile specimens (a) $0.0025 \mathrm{~mm},\left[0^{\circ}, 0^{\circ}\right]$; (b) -0.0025 $\mathrm{mm},\left[0^{\circ}, 0^{\circ}\right]$; (c) $0.0025 \mathrm{~mm},\left[+45^{\circ},-45^{\circ}\right]$; (d) $-0.0025 \mathrm{~mm},\left[+45^{\circ},-45^{\circ}\right] \ldots \ldots \ldots \ldots \ldots \ldots \ldots . .17$

Figure 11: Percentage contribution of factors on strength of printed parts.................... 18

Figure 12: Four stages of bond formation. ............................................................ 19

Figure 13: Apparent contact and true contact are ....................................................... 22

Figure 14: Sketch of two rows of contact with raster orientation of $\left[0^{\circ}, 90^{\circ}\right] \ldots \ldots \ldots \ldots \ldots . .22$

Figure 15: Dependence of the second moment of inertia ratio, $\xi$, on $\gamma$ and k................ 26

Figure 16: Specimen preparation and the layer orientation .......................................... 28

Figure 17: An SEM micrograph showing the contacts between polycarbonate layers in bending test fracture with raster gaps of (a) $0.050 \mathrm{~mm}$ and (b) $-0.025 \mathrm{~mm}$................... 30

Figure 18: Comparison between material assumed as homogeneous and with the model applied in the cases where the raster angle is $\left[+30^{\circ},-60^{\circ}\right]$ and $\left[+45^{\circ},-45^{\circ}\right] \ldots \ldots \ldots \ldots \ldots \ldots \ldots . . . . . . . . .32$

Figure 19: Flowchart of a model to investigate the deformation of FDM printed parts.. 35

Figure 20: Heat transfer modes and the computational domain ...................................... 36

Figure 21: Type of contact in a raster for the heat transfer model................................... 37

Figure 22: Principle of structure of thermal plastic..................................................... 40

Figure 23: Part geometry used in the modelling work.................................................. 41

Figure 24: Temperature history of printed part. ………………………………….... 42 


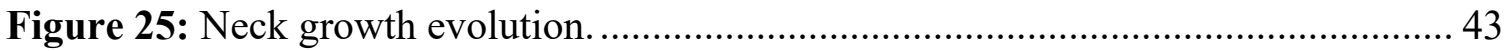

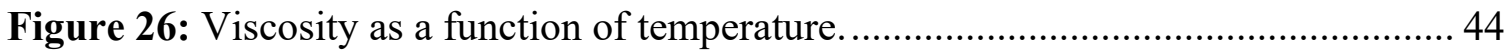

Figure 27: Temperature history of deposited raster with different value of fraction of

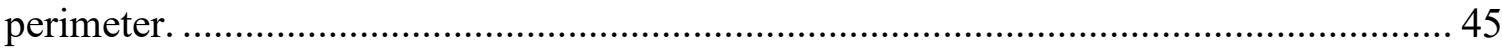

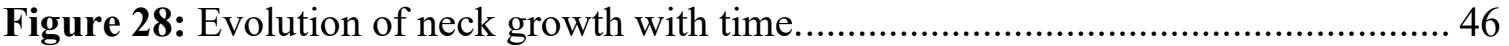

Figure 29: Measurements of the true contact of adjacent rasters (a) $\left[0^{\circ}, 0^{\circ}\right], 0.000 \mathrm{~mm} .47$ 


\section{LIST OF TABLES}

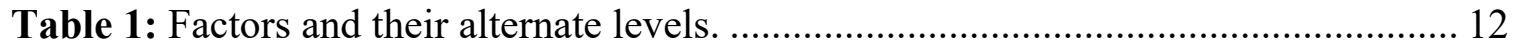

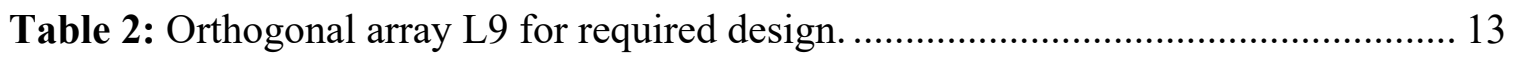

Table 3: Tensile and bending strength of printed parts, layer thickness of $0.254 \mathrm{~mm}$... 13

Table 4: Values of the effective second moment of inertia ratio $(\xi)$ corresponding to the

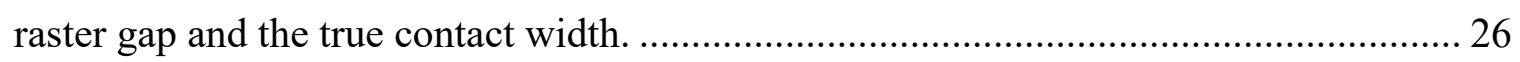

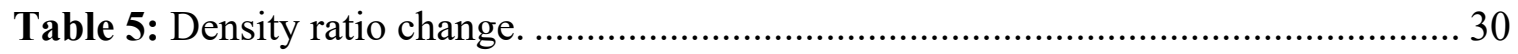

Table 6: Standard deviation of cohesive strength and the apparent strength.................. 33

Table 7: Polycarbonate (PC) properties used in the study......................................... 40

Table 8: Comparison of the measured and the predicted bond lengths. ......................... 48 


\section{LIST OF ABBREVIATIONS}

$\begin{array}{ll}\text { AM } & \text { Additive manufacturing } \\ \text { ANOVA } & \text { Analysis of variations } \\ \text { ASTM } & \text { American society for testing and materials } \\ \text { CAD } & \text { Computer aided design } \\ \text { DOE } & \text { Design of experiments } \\ \text { FDM } & \text { Fused deposition modeling } \\ \text { FFF } & \text { Fused filament fabrication } \\ \text { PC } & \text { Polycarbonate } \\ \text { SEM } & \text { Scanning electron microscopy }\end{array}$




\author{
A COMBINED ANALYTICAL AND EXPERIMENTAL APPROACH FOR \\ PREDICTION PROPERTIES OF FUSED DEPOSITION MODELING (FDM) PARTS \\ Thao Thi Phuong Phan \\ Dr. Robert Andy Winholtz, Dissertation Supervisor
}

\begin{abstract}
Fused Deposition Modeling (FDM) is a technique used to build rapid prototypes out of thermoplastic materials. Printing technology continues to mature from a rapid prototyping process to a rapid manufacturing technique, therefore predicting printed part behavior has become increasingly desirable. This study aims to determine the relation between the process parameters and associated temperature history and the strength of printed parts. A combined analytical and experimental approach was used for studying and prediction properties of printed parts. The results indicate that process parameters and temperature history have a significant impact on the behavior of printed parts. Further research is needed to identify other factors that could improve the effectiveness of printed part behavior.
\end{abstract}




\section{Introduction}

Fused deposition modeling (FDM) is an effective additive manufacturing (AM) technique because of its capacity for building complex structures at low cost compared with other AM methods. In the FDM process, filament material is heated and extruded in the semi-molten state to form rasters which make up layers needed for building the required structure.

In order to use the FDM printed parts in service, the printed parts have to work under actual load. Therefore, predicting and optimizing printed part strength has become increasingly desirable. The objectives of the study are (i) studying the behavior of printed parts by doing actual physic testing, and (ii) development of a predictive model for strength and bonding of printed parts.

This dissertation presents and shows the results in: (i) the influence of process parameters on the mechanical properties of the FDM part by using design of experiments (DOE) on the polycarbonate filament, (ii) development of a combined analytical and experimental approach for the determination of the strength between layers taking the true contact area into account in order to better understand the cohesion between layers and introducing a new method of mechanical properties testing for FDM test specimens, (iii) the modified model of an existing heat transfer and sintering model to study the effect of temperature on the true contact of the adjacent rasters of the FDM part, demonstrating the need to accurately determine the relevant heat transfer and heat transfer coefficient. 


\section{Background}

Additive manufacturing ( $\mathrm{AM}$ ), also known as 3D printing, has been under developments for approximately 30 years and is characterized by introducing a freedom in compared to conventional manufacturing methods. AM can be used to create complex geometries (even full moving assemblies) that would be difficult or impossible to achieve with traditional manufacturing methods. These complex geometries can be stronger and lighter than their traditionally manufactured counterparts. Fused deposition modeling (FDM), a branch of the AM family, is also called fused filament fabrication (FFF). FDM was patented by Crump, S.S. in 1992 [1] and 3D printers based on FDM have been produced by the Stratasys Corporation for years [2]. FDM is a low cost process using semimolten filaments of plastic material on a build platen. FDM products nowadays are used not only for visualization in modeling but also in the biomechanics and aerospace fields because of their high strength-to-weight (S/W) ratio [3].Fig. 1 [4] illustrates this for a patient's missing orbital (left) and an aircraft nozzle which has saved up to $90 \%$ in manufacturing time and reduced cost $63 \%$ (right).
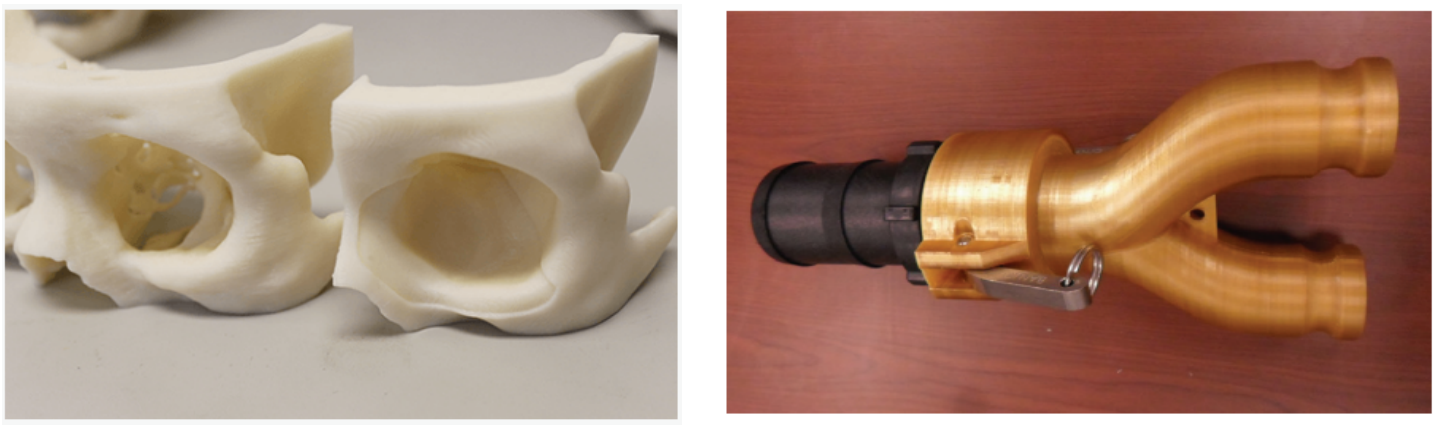

Figure 1: FDM applications, orbital replacement bio implant (left) and an aircraft nozzle (right). 
FDM is the best-known technique in additive manufacturing because of its advantages in the cost effectiveness and availability of the equipment, the short lead times in delivery, and the wide range of choice in plastic materials. However, FDM has the disadvantages of anisotropic properties depending on process parameters, dimensional accuracy dependent on the process parameters and thermal history, often time consuming and post processing requirements depending on the complexity of the design.

In the FDM process, objects are built by depositing filaments of hot polymer in the softened state that fuse together when they cool and harden with or without a build chamber. Materials used for the FDM process are mainly thermoplastic polymers to build complicated shapes with acceptable tolerances [5,6]. A simple schematic of typical FDM printer is shown in Fig. 2 [7]. The feed mechanism is connected to the extrusion nozzles, one nozzle for model material and one nozzle for the support material. The extrusion nozzles translate in the XY-plane of the printing platform to create the geometry shape in each layer. The build platform moves down after each successive printed layer and a new layer is deposited. This process is repeated until the final part is complete.

In FDM, raster angle, raster gaps, raster width, contour width, slice thickness and build orientation (flat, on-edge, upright) are the important geometrical parameters that influence the strength of the product under a set of processing conditions; these parameters are illustrated in Fig. 3 [8]. 

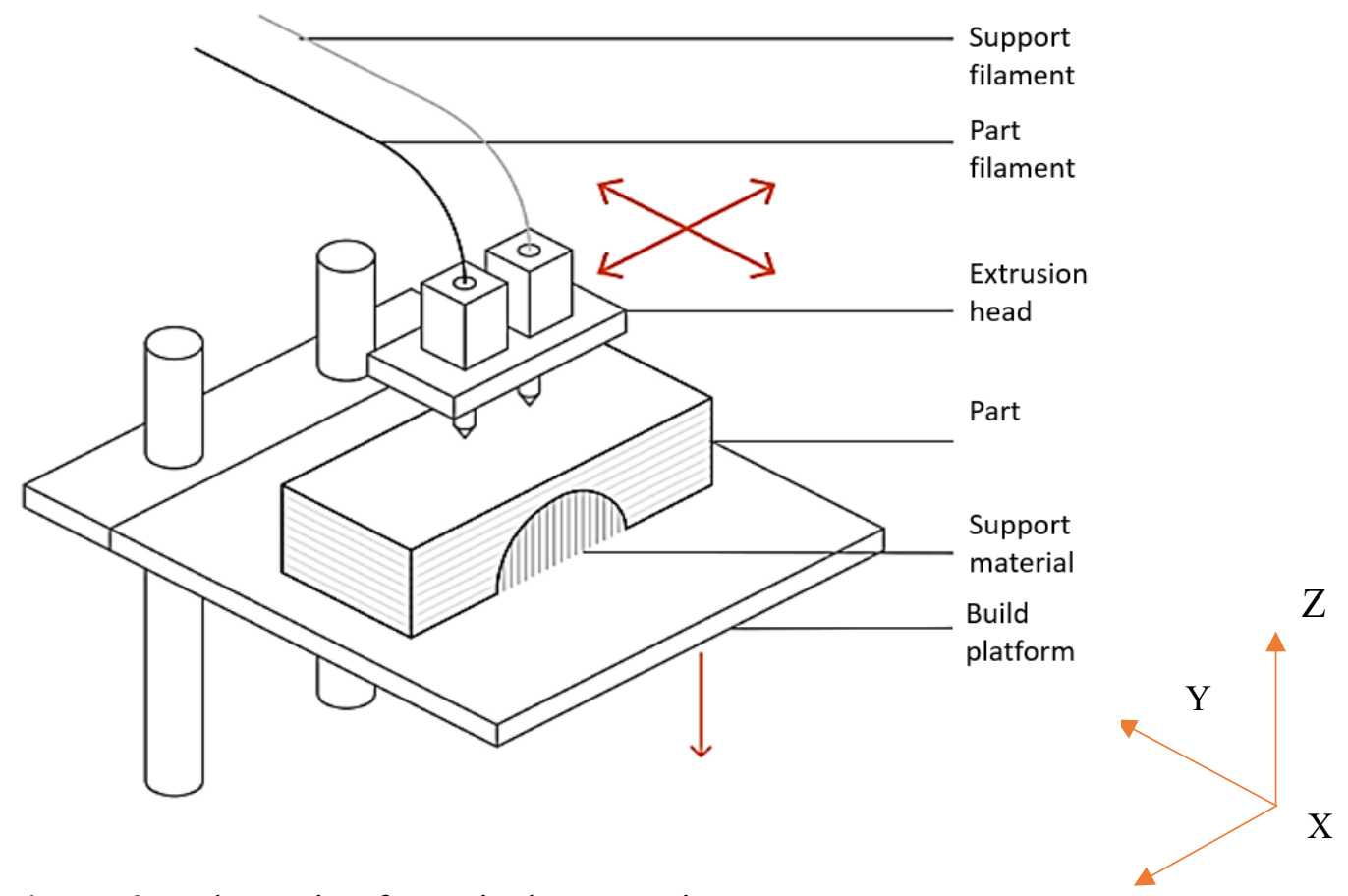

Figure 2: Schematic of a typical FDM printer.
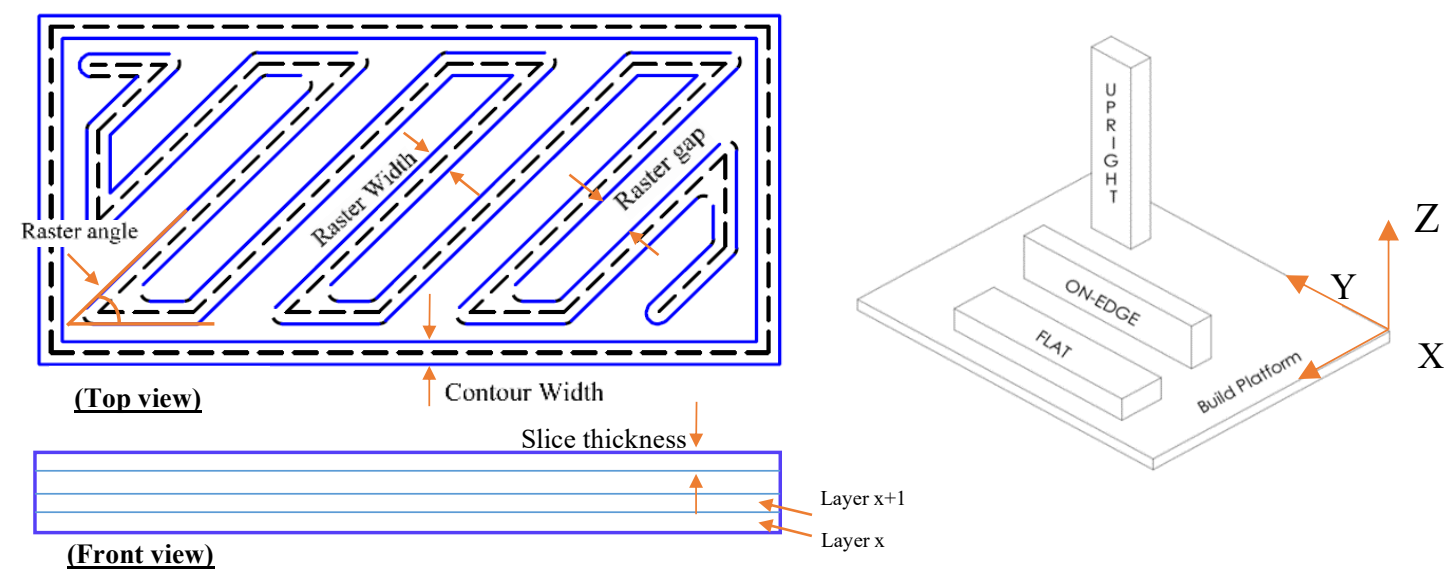

Figure 3: Working parameters of FDM process - ISO/ASTM52921 - 13 standards. 
Slice thickness, as shown in Fig. 3, refers to the thickness of each layer of material deposited by the FDM nozzle. When the slice thickness increases, the forming accuracy and the surface quality decrease and the printing time decreases. Inversely, the forming accuracy and the surface quality increase and the printing time increases when the slice thickness decreases [9]. Build orientation as shown in Fig. 3, refers to the orientation angle of the product built on the build platform. Build orientation affects print time, support structure and surface finish. By doing tensile testing with the same set of process parameters and adjusting only the build orientation, [10] shows that the flat build orientation gives the highest strength, the up-right orientation gives the lowest strength and the on-edge build orientation gives the intermediate strength in mechanical properties of the printed parts. The raster width, as shown in Fig. 3, refers to the width of the deposition path and is related to the nozzle tip size.

The raster gap refers to the distance between two adjacent rasters in a layer. The raster gap value can be negative (overlapping), zero (in contact), or positive (not in contact) as shown in Fig. 4. The raster angle refers to the angle between the raster and the $\mathrm{X}$-axis of the printing platform. The raster angle can be the same or different successive in layers as shown in Fig. 5. Similar to composite materials where the orientation of the fiber in the matrix governs material properties, the raster gap and the raster angle govern layer properties by defining the density and how the raster is oriented in each layer. 

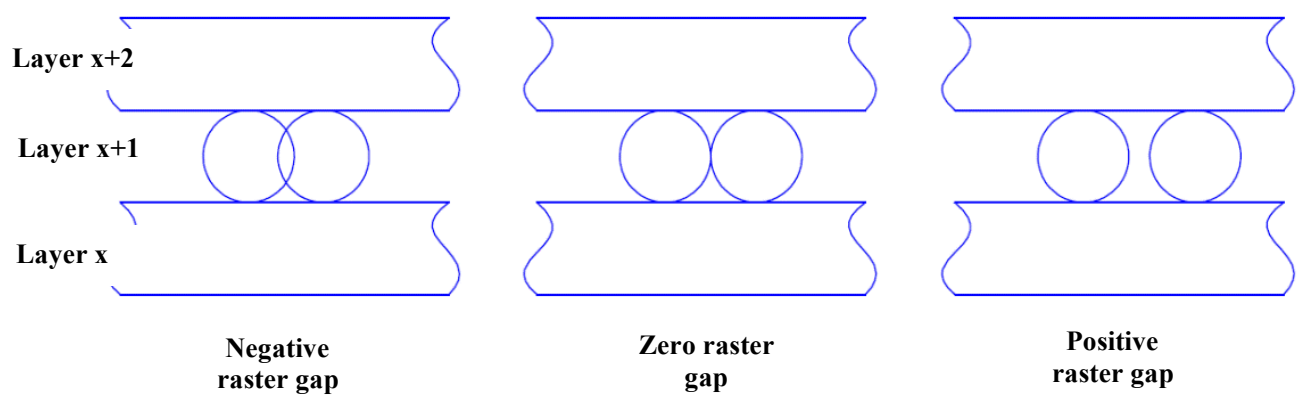

Figure 4: Raster gap type.

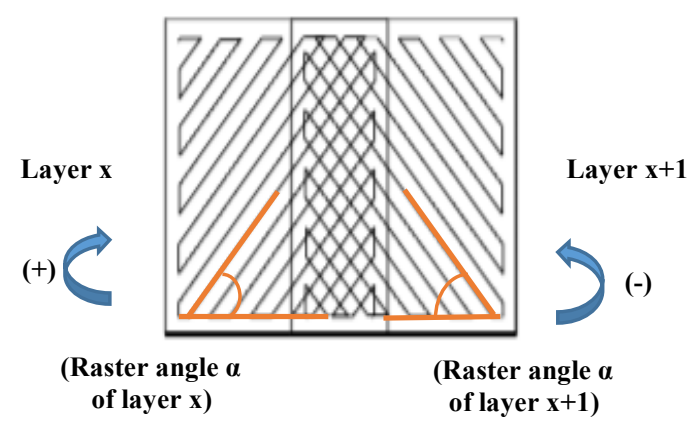

Figure 5: Raster angle type.

\section{Literature review}

Despite increased attention from the academy and industry in recent years, there are still a few fundamental questions regarding FDM awaiting answers like the requirements on the material properties and the optimization of the strength for a FDM. These questions reflect the nature of FDM as a controlled manufacturing process in an additive manner, heat transder and phase transition of the material. There is a long way to go to reach a complete conception of FDM, the understanding of which is a prerequisite before this rapid prototyping and additive manufacturing technique can reach its full potential.

The bonding strength of FDM parts is determined by thermal process during 
deposition. The build temperature must be higher than the glass transition temperature and it must be kept there sufficiently long at contact to establish bonding between rasters [5,1113]. The extrusion temperature has a more significant impact on the neck growth in the bonding zone than the envelope temperature does. Poor mechanical properties of the bonding zone are a result of insufficient time at temperature for bonding [14]. The bonding between two adjacent rasters occurs at surface contacts in four stages: neck formation, diffusion, neck growth, and randomization [5,11]. Costa et al. [11] experimentally examined the contributions of conduction, convection and radiation to the bonding level inside FDM parts. They stated that conduction and convection have more significance to the resulting mechanical properties compared to radiation. Sun [12] suggested the nonisothermal degree of healing evolution characterized as a ratio between the strength of a fully healed interface and the existing stress in an FDM part as a function of time. Coogan et al. [13] predicted bond strength caused by diffusion, wetting, and the effect of temperature within the printed part. They used aligned rasters in their simulation. Ang et al. [15] found a logarithmic relationship describing the correlation between the variation of offset compressive yield strength and porosity. Rayshkewitch et al. [16] also found a relation between the compressive strength on the degree of porosity of the structure. Wool et al. [17] defined the degree of self-healing $(\sigma)$ between interfaces for thermoplastic polymers, characterized as the ratio of interface strength to bulk material strength, as a function of contact time to the power of $1 / 4$. Mohamed et al. [18] confirmed that all parameters could be used effectively for improvement in dynamic mechanical properties as a function of temperature. H. Xia et al. $[19,20]$ presented a fully resolved numerical simulation of FDM in terms of fluid low, solidification, residual stresses, and modelling of 
the nozzle geometric features. The promising result of this study indicates that the converged solution in the shape of the filament and the proper temperature distribution occurs by integrating a grid refinement process in the finite volume method. However, the evolution of the configuration tensor was not taken into account and therefore the applicability of this model to more complicated material models is limited.

The strength and stiffness of FDM parts typically have been investigated using tensile testing on standard dog-bone specimens. The effects of different deposition strategies, including raster angle, raster gaps, raster width, raster height, contour width, and build orientation have been evaluated. The cross-sectional area of the specimen at the failure region has usually been considered as the apparent one. Therefore, the specimen porosity was not included in the cross section area [5,21-23]. Design and optimization of manufacturing processes involving many parameters such as the FDM manufacturing process requires statistical design of experiments (DOE) [24] in order to have reliable results with minimum trials. S. Rohde et al. [25], found that FDM built specimens with different raster angles result in different tensile strengths, Young's moduli, and yield strengths. The effect of the layer thickness on the strength and stiffness were studied with a suggestion on the optimum thickness for best properties [26]. Jonathan et al. [27] presented an approach for mechanical property optimization of FDM parts using the design of experiments. The study showed the effects of layer thickness, perimeter layers, and infill level on surface finish and strength of FDM built parts. Similar effects of the major process parameters on properties of FDM built parts were also confirmed by other investigators $[28,29]$. The fiber orientation (raster angle) on each layer and the stacking sequence of various layers affect mechanical properties of fusion deposition build structures and lead 
to anisotropic behavior of the FDM built structure. Intended properties and specific loading conditions must be considered during the design of FDM-built products in order to avoid premature failures [17, 21-25]. Classical laminate theory is used in this study to calculate effective bulk properties from the number and orientation of the layers. It can be used as a design aid to select a deposition strategy based on stiffness and strength requirements for part design [30-32] as well as predicting failure under different conditions [14,33]. The deformation behavior was investigated and the optimization of wrap deformation along with dimension errors has been studied in Panda et al. [34] and Zhang and Peng [35]. Wang et al. [36] proposed a mathematical model for wrap deformation. Vatani et al. [37] predicted a distortion of FDM parts by using classical lamination theory. Yu [38] examined the effect of deposition patterns on the resulting stresses and deflections. Liu Xinhua [39] presented a theoretical model based on the theory of thermos- elasticity. However, the theoretical model was shown to deviate from the actual value due to simplification of the assumptions by Chen Baojuan [40]. Very recently, a review article [41] was published which described the needs for future research and desirable objectives for FDM technology. 


\section{Methodology and Modeling}

\subsection{Experimental study of mechanical properties of FDM parts}

FDM is a manufacturing processes involving many parameters as shown in Fig. 6 [21]. The working parameters, part build orientation, environment factors, concept models, unprocessed material, and FDM machine are all factors which contribute to the final quality and mechanical properties of the printed parts. It is difficult to cover all the process parameters in an individual study, therefore, breaking down the parameters to a smaller set and studying the effect of them on the mechanical properties of printed parts are the approach.

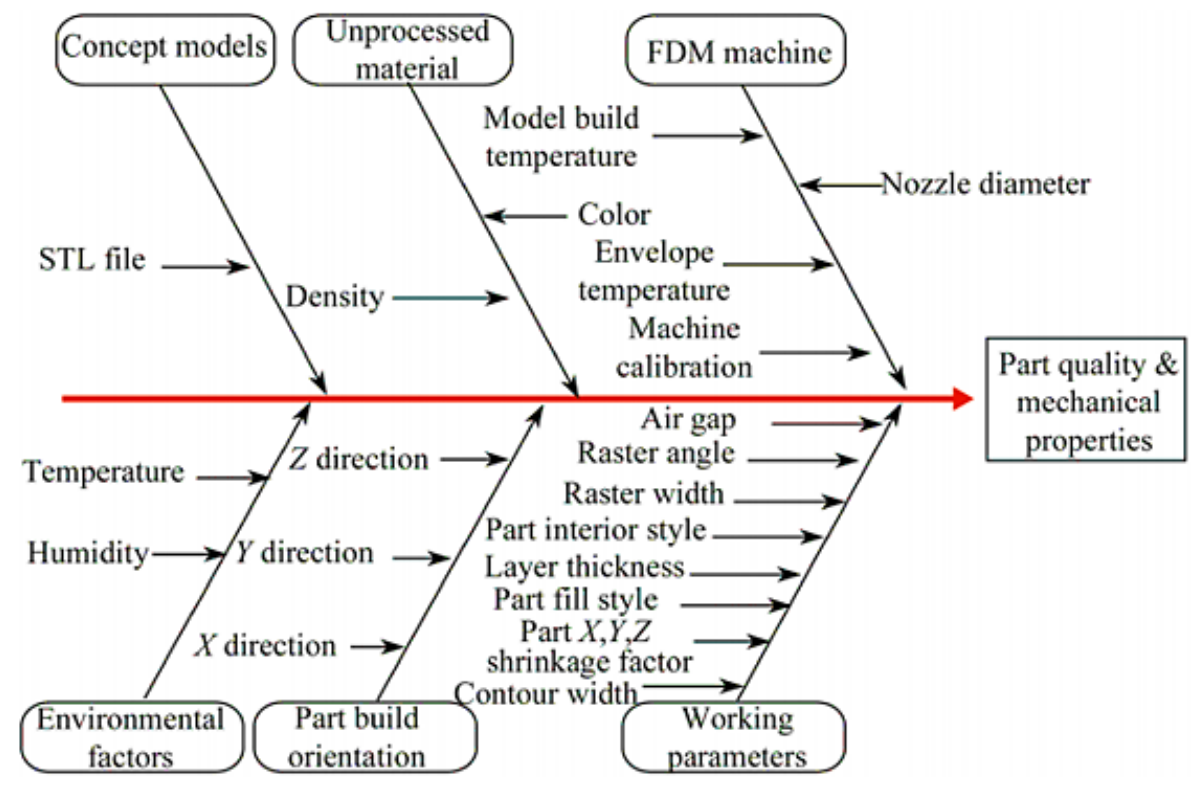

Figure 6: Cause and effect diagram of FDM process parameter. 
The working parameters, including raster gaps (i.e. air gaps), raster angle, and layer thickness, were chosen for the study of mechanical properties of FDM parts. Tensile and bending were done to determine the mechanical properties. Design of experiments was used in designing the experiments and data analysis. Image-based analysis was used to analyze the inner structure of the printed parts on their fracture surfaces.

\section{Specimen preparation and experimental procedures}

The specimens for the tensile tests were designed following the standard ASTM D638 test specimen and shown in Fig. 7a [42]. The specimens for the bending tests were designed following the standard ASTM D790 test specimen and shown in Fig. 7b. All of the specimens were printed with a Stratasys Fortus $400 \mathrm{mc}$ with a part dimensional accuracy of $\pm 0.127 \mathrm{~mm}(0.005 \mathrm{in})$. The flat build orientation was used for the tensile specimens and the upright orientation was used for the bending specimens. Manufacturing parameters were customized selected. Raster gaps were -0.001 in $(-0.025 \mathrm{~mm}), 0.000$ in $(0.000 \mathrm{~mm})$ and -0.002 in $(-0.051 \mathrm{~mm})$. The raster angle were selected as $\left[0^{\circ}, 0^{\circ}\right],\left[+30^{\circ},-\right.$ $\left.60^{\circ}\right]$ and $\left[+45^{\circ},-45^{\circ}\right]$. The layer thickness were selected as 0.010 in $(0.254 \mathrm{~mm})$ and 0.0130 in $(0.330 \mathrm{~mm})$.

Tensile and bending tests were carried out on an ADMET universal testing machine, eXpert2600 with default settings, sampling at 100 samples/sec, and a load cell of 2250.0 (lb), axial strain gauge length of 2.0 (in), and a transverse strain gauge length of 1.0 (in). The fracture surfaces of the tensile specimens were examined with scanning electron microscopy (SEM) using a FEI Quanta 600, microscope. 
(a)

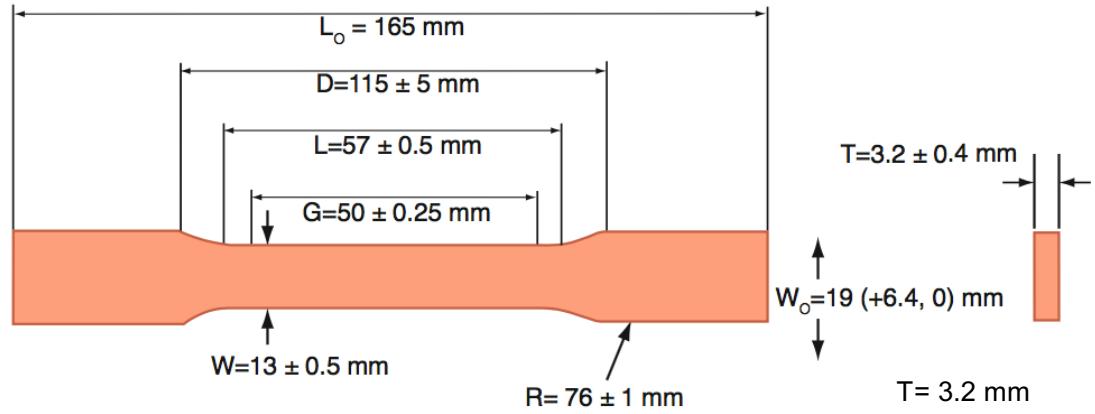

(b)

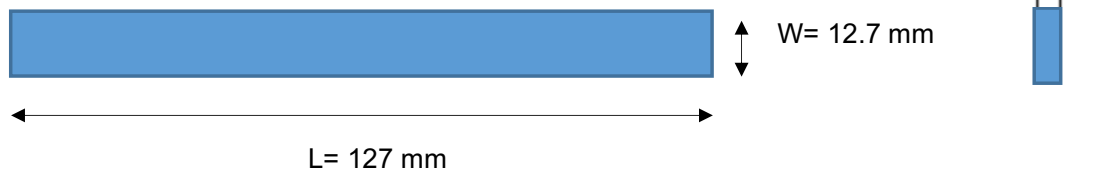

Figure 7: (a) Specimen for the tensile test and (b) bending test.

The design of experiments (DOE), ANOVA (Analysis of Variances) method, was used to estimate the percentage contribution of each parameter into the strength of printed parts for both tensile test and bending test. The Table 1 shows the factors and their levels and Table 2 shows the orthogonal array L9 for required design. Based on L9 table, each set of levels of factor was tested three times. Therefore, the total number of specimens is 27 for tensile testing and 27 for bending testing.

Table 1: Factors and their alternate levels.

\begin{tabular}{|l|c|c|c|}
\hline \multirow{2}{*}{ Factors } & \multicolumn{3}{c|}{ Levels } \\
\cline { 2 - 4 } & 1 & 2 & 3 \\
\hline (A) Raster Gap, mm & -0.0025 & 0 & 0.0025 \\
\hline (B) Raster angles, ${ }^{\circ}$ & {$\left[0^{\circ}, 0^{\circ}\right]$} & {$\left[+30^{\circ},-60^{\circ}\right]$} & {$\left[+45^{\circ},-45^{\circ}\right]$} \\
\hline (C) Layer thickness, $\mathrm{mm}$ & 0.254 & 0.330 & 0.254 (dummy) \\
\hline
\end{tabular}


Table 2: Orthogonal array L9 for required design.

\begin{tabular}{|c|c|c|c|}
\hline Exp No. & (A) Raster Gap & (B) Raster angles & (C) Layer thickness \\
\hline 1 & 1 & 1 & 1 \\
\hline 2 & 1 & 2 & 2 \\
\hline 3 & 1 & 3 & 2 \\
\hline 4 & 2 & 1 & 3 \\
\hline 5 & 2 & 2 & 1 \\
\hline 6 & 2 & 3 & 3 \\
\hline 7 & 3 & 1 & 2 \\
\hline 8 & 3 & 2 & 3 \\
\hline 9 & 3 & 3 & \\
\hline
\end{tabular}

$\underline{\text { Results and Discussion }}$

Table 3: Tensile and bending strength of printed parts, layer thickness of $0.254 \mathrm{~mm}$.

\begin{tabular}{|c|c|c|c|c|}
\hline & Raster gap (mm) & -0.0025 & 0.000 & 0.0025 \\
\hline \multirow{3}{*}{$\begin{array}{l}\text { Tensile strength } \\
(\mathrm{MPa}) \\
\text { (Flat build } \\
\text { orientation) }\end{array}$} & Raster angles $\left[+0^{\circ},-0^{\circ}\right]$ & $\begin{array}{l}45.34 \\
(3.15)\end{array}$ & $\begin{array}{l}40.32 \\
(5.92)\end{array}$ & $\begin{array}{l}25.12 \\
(4.04)\end{array}$ \\
\hline & Raster angles $\left[+45^{\circ},-45^{\circ}\right]$ & $\begin{array}{l}69.60 \\
(4.54)\end{array}$ & $\begin{array}{l}51.11 \\
(4.09)\end{array}$ & $\begin{array}{l}29.45 \\
(4.38)\end{array}$ \\
\hline & Raster angles $\left[+30^{\circ},-60^{\circ}\right]$ & $\begin{array}{l}46.33 \\
(4.81)\end{array}$ & $\begin{array}{l}41.23 \\
(2.89)\end{array}$ & $\begin{array}{l}30.25 \\
(4.11)\end{array}$ \\
\hline \multirow{3}{*}{$\begin{array}{l}\text { Bending strength } \\
\text { (MPa) } \\
\text { (Upright build } \\
\text { orientation) }\end{array}$} & Raster angles $\left[+0^{\circ},-0^{\circ}\right]$ & $\begin{array}{l}33.89 \\
(3.68)\end{array}$ & $\begin{array}{l}33.23 \\
(3.31)\end{array}$ & $\begin{array}{l}29.66 \\
(2.45)\end{array}$ \\
\hline & Raster angles $\left[+45^{\circ},-45^{\circ}\right]$ & $\begin{array}{l}37.20 \\
(4.31)\end{array}$ & $\begin{array}{l}34.35 \\
(3.98)\end{array}$ & $\begin{array}{l}30.23 \\
(4.38)\end{array}$ \\
\hline & Raster angles $\left[+30^{\circ},-60^{\circ}\right]$ & $\begin{array}{l}32.78 \\
(2.27)\end{array}$ & $\begin{array}{l}32.56 \\
(5.10)\end{array}$ & $\begin{array}{l}29.12 \\
(5.45)\end{array}$ \\
\hline
\end{tabular}


Table 3 shows the quantitative data for the strength of FDM printed parts with different raster gaps, raster angles for both the tensile test and bending test. Each data set was tested three times. The numbers inside parentheses is the standard deviation value. The data set for both tensile and bending tests for layer thicknesses of $0.254 \mathrm{~mm}$ and $0.330 \mathrm{~mm}$ are similar, therefore the Table 3 shows the data for layer thickness $0.254 \mathrm{~mm}$ only. The number on the parenthesis is the observed standard deviation. For both tensile and bending tests, the strength of the printed part decreases corresponding to an increase in the raster gaps. Also, the strength of the printed part increases going from the raster angles of $\left[+0^{\circ}\right.$,$\left.0^{\circ}\right]$, to $\left[+30^{\circ},-60^{\circ}\right]$, to $\left[+45^{\circ},-45^{\circ}\right]$. The trend of these results matches the results of [30-32] which used the classical laminate theory to explain the effect of the working parameters to the strength of the printed parts. The tensile tests were done with the upright build orientation (Appendix D) which also shows the effect of raster gaps on the mechanical properties of printed parts. Moreover, the difference between tensile strength and the bending strength is that the nature of the stress and strain states in tension and bending are not the same. With a tensile test, the maximum tensile stresses are experienced throughout the entire gage volume and surface area of the specimen; in bending where the sample sees tensile stress above the neutral axis and compressive stresses below, the maximum tensile stresses are in contrast concentrated in a small region on the top surface above the neutral axis. Accordingly for similar sized specimen, the tensile specimen sees the maximum stresses throughout its entire gauge volume, i.e., over a much larger volume than the corresponding bend specimen. Moreover, each layer has a rounded end which come together with a stress concentration as shown in Fig.8 [7]. These edges give a stress concentration under loading. 


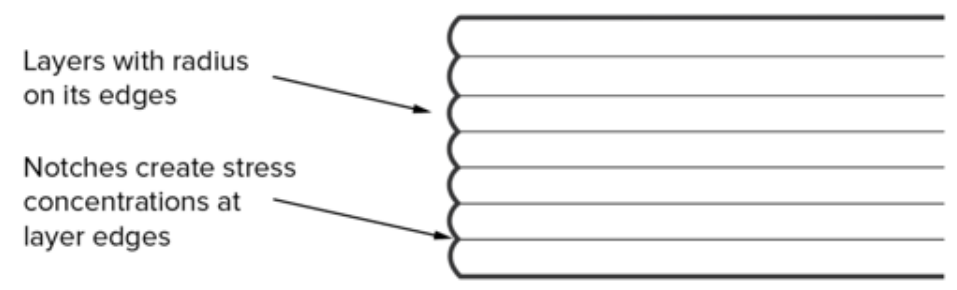

Figure 8: Notches creates stress concentrations at layer edges.

Fig. 9 and Fig. 10 show the fracture surface from the bending and tensile tests respectively. For both cases, the positive raster gaps $(0.0025 \mathrm{~mm})$ leads to the gap between adjacent rasters in a layer. The negative raster gaps $(-0.0025 \mathrm{~mm})$ leave a small or no gap between adjacent rasters in a layer making the printed part like-solid material. This can be explained by the overlapping of adjacent rasters. The more negative of raster gaps, the more dense the internal structure is. The positive raster gap gives a better view of the inner structure of the oriented parts on the fracture surfaces. On the fracture surface of the bending test as shown in Fig. 9a, when bending load parallel to the layers, there are marks on the raster in the layer shown from the separation of the rasters in the layer above. These are places of the heated rasters blend to each other. These marks also show in fracture surface of negative raster gaps as shown in Fig. 9b. At fracture surface of tensile test as shown in Fig. 10a and Fig. 10b, these marks are difficult to see because the tensile load parallel to the layers as the rasters in layers is stretched until broken. However, they shows indentation of upper adjacent raster to the lower one. It is obvious that the weight of the raster cannot be negligible and should be considered in analysis and modeling. 

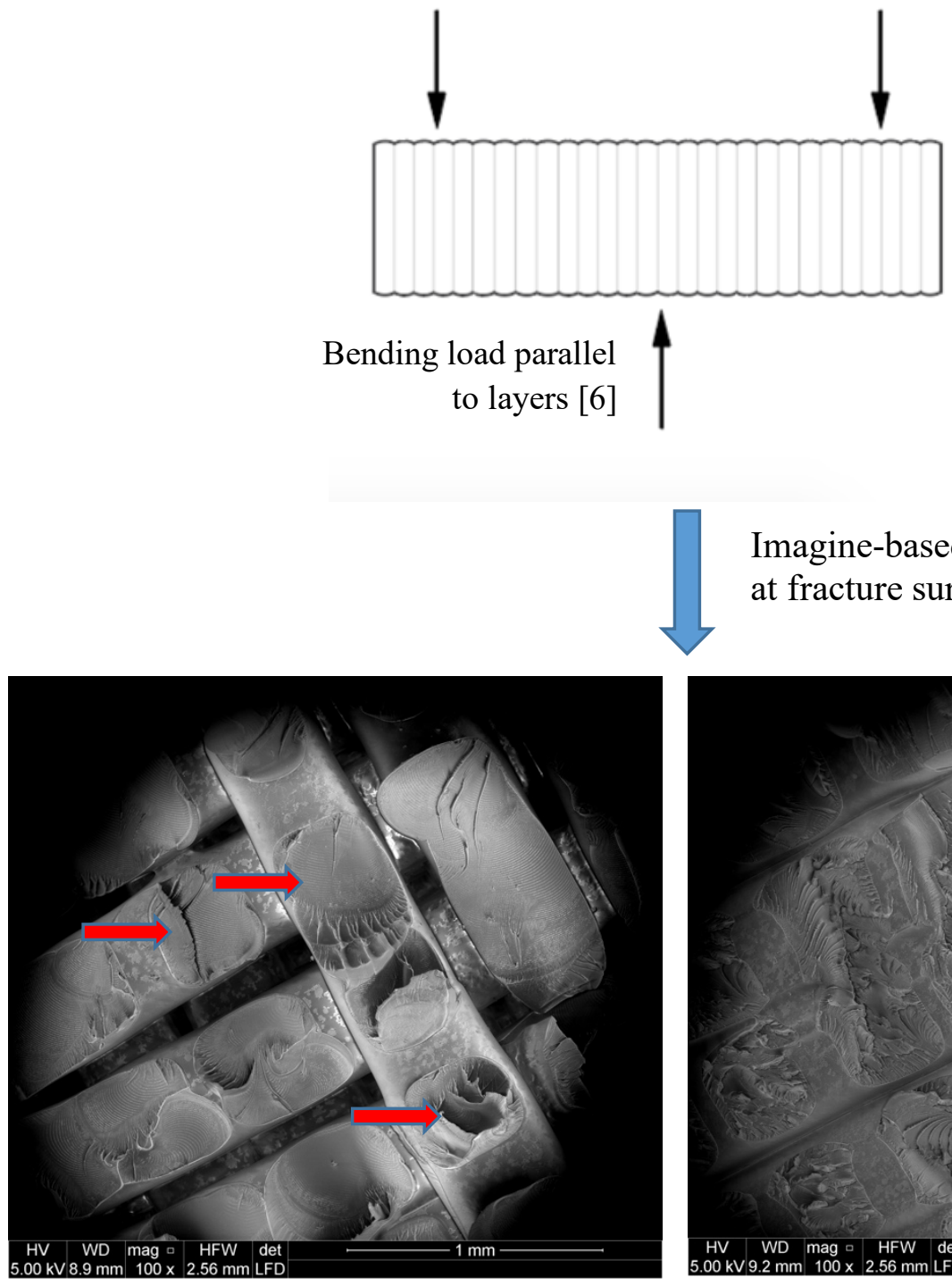

Imagine-based analysis at fracture surface

(a) $0.0025 \mathrm{~mm},\left[+30^{\circ},-60^{\circ}\right]$

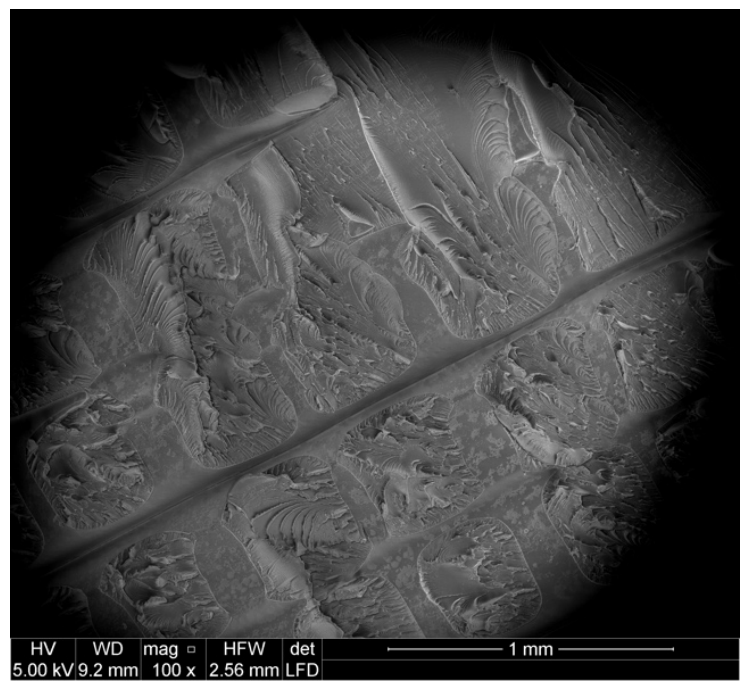

(b) $-0.0025 \mathrm{~mm},\left[+30^{\circ},-60^{\circ}\right]$

Figure 9: Fracture surface of the bending specimens (a) $0.0025 \mathrm{~mm},\left[+30^{\circ},-60^{\circ}\right]$; (b) $0.0025 \mathrm{~mm},\left[+30^{\circ},-60^{\circ}\right]$. 
Tensile load parallel to layers [6]

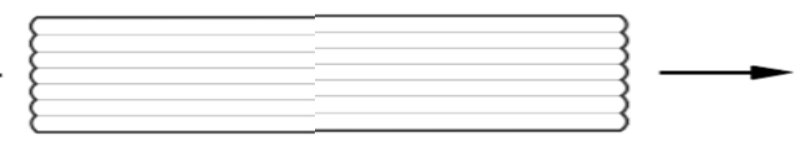

Imagine-based analysis at fracture surface

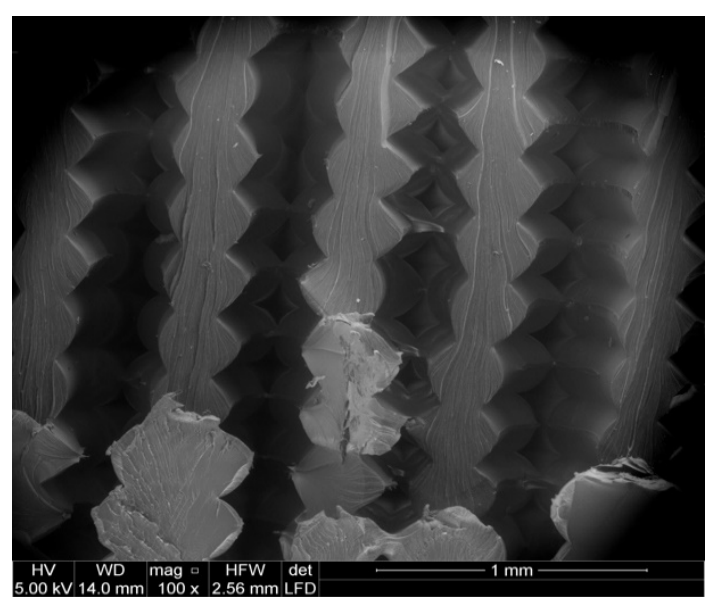

(a) $0.0025 \mathrm{~mm},\left[0^{\circ}, 0^{\circ}\right]$

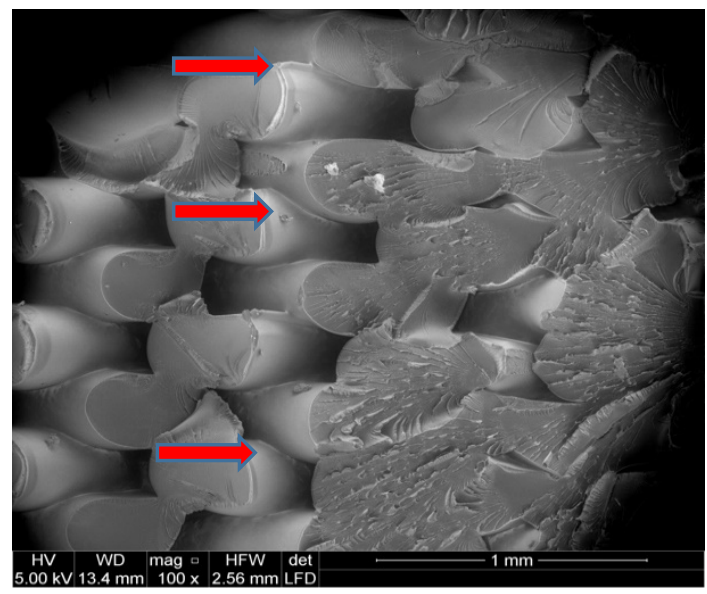

(c) $0.0025 \mathrm{~mm},\left[45^{\circ}, 45^{\circ}\right.$;

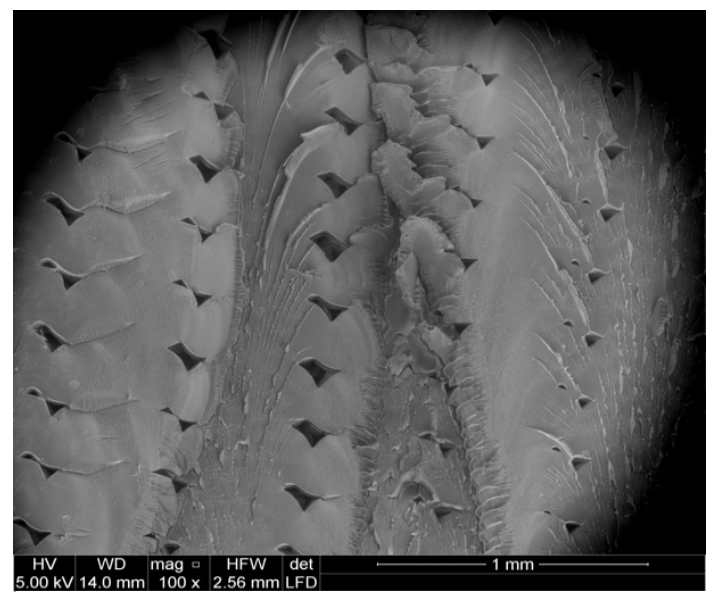

(b) $-0.0025 \mathrm{~mm},\left[0^{\circ}, 0^{\circ}\right]$

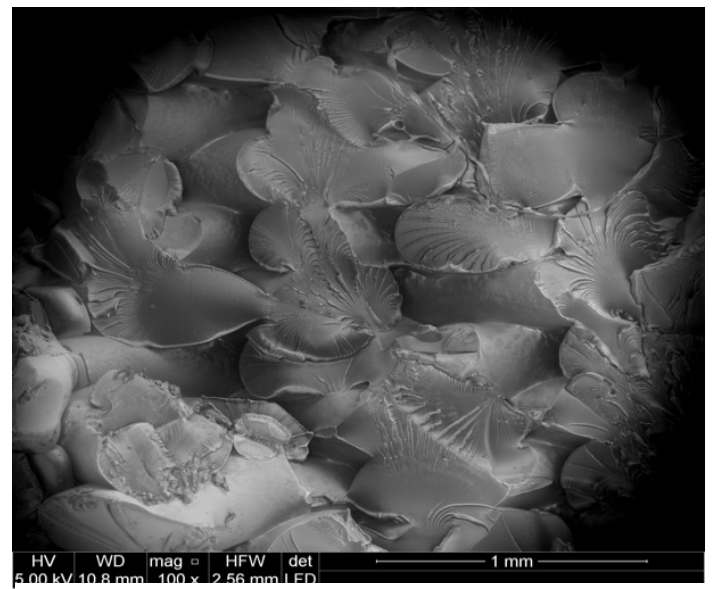

(d) $-0.0025 \mathrm{~mm},\left[45^{\circ}, 45^{\circ}\right]$;

Figure 10: Fracture surface of the tensile specimens (a) $0.0025 \mathrm{~mm},\left[0^{\circ}, 0^{\circ}\right]$; (b) -0.0025 $\mathrm{mm},\left[0^{\circ}, 0^{\circ}\right]$; (c) $0.0025 \mathrm{~mm},\left[+45^{\circ},-45^{\circ}\right]$; (d) $-0.0025 \mathrm{~mm},\left[+45^{\circ},-45^{\circ}\right]$. 
The summary chart from the DOE in Fig. 11 shows the percentage contribution of each factor (raster gaps, raster angles, layer thickness) on the strength in tension and bending of the printed parts. It is obvious that the raster gap factor has the highest contribution to yield strength for both tests. These results are expected because the negative gaps lead to denser layers and fewer voids in the structure, generally. The raster angles factor has the intermediate contribution. The layer thickness has the least contribution to the strength. Similar work has been done with Ultem filament (Appendix C) which also shows the most significant contribution from raster gaps on the mechanical properties of printed parts.

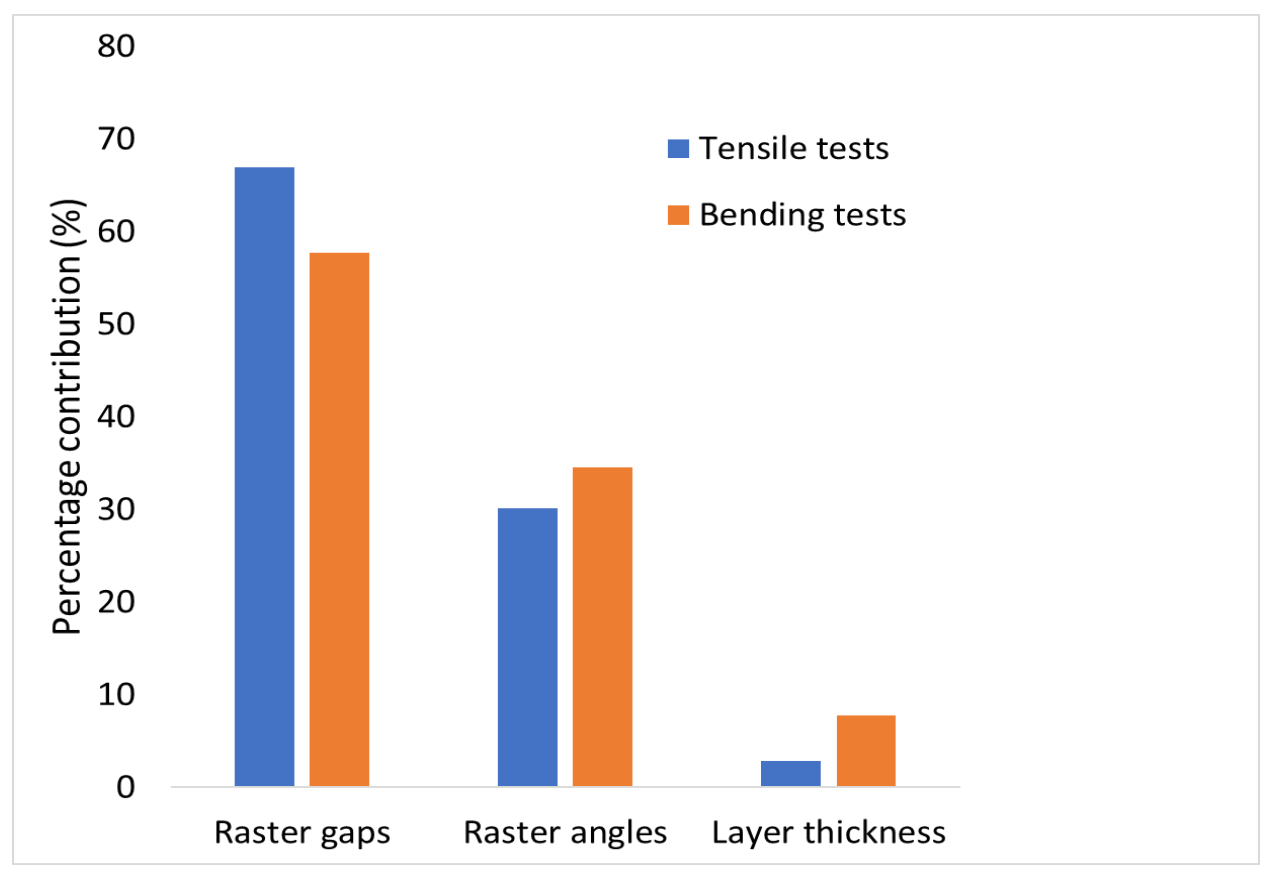

Figure 11: Percentage contribution of factors on strength of printed parts.

In conclusion, the mechanical properties of FDM printed parts in two studies (tensile and bending) shows the influence of the working parameters on the properties of parts. From these studies, the raster gaps and raster angles are the interesting factors for 
further study. The introduction of a cohesive strength prediction model is introduced in the next section.

\subsection{Cohesive strength in FDM parts}

Cohesion refers to the ability of two contiguous surfaces of the same material to form a strong bond. A fairly good coalescence of both surfaces of the material takes place at contact. Good cohesive cannot occur without sufficient coalescence. As mentioned earlier in the literature review, the formation of bonds between polymer heated filaments in the FDM process can be described with four stages: (i) surface contacting, (ii) neck growth, (iii) diffusion at interface, (iv) randomization, as shown in Fig. 12 [43].

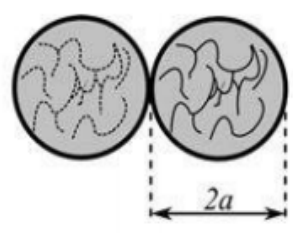

1) surface contact

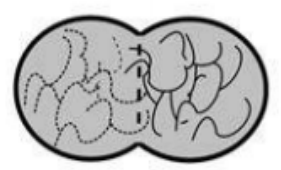

3) diffusion and neck growth

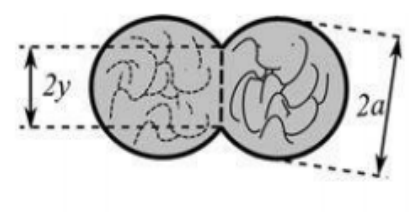

2) neck formation

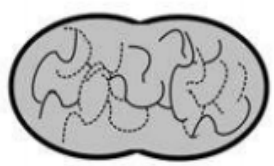

4) randomization

Figure 12: Four stages of bond formation.

The raster will spread into an oblong shape after extrusion. The final shape depends on the viscosity of the melt and the relative surface energies of the raster and the previous surface. As it spreads, it cools and the viscosity increases until a solid state is reached. The strength of the bond, the overall mechanical properties of the part, depend on the contact area and the size of the voids. 
Ideally, if the coalescence between two roads is $100 \%$, all voids are completely eliminated. However, in the actual case, especially in FDM, the internal voids between the roads or layers are impossible to be eliminated due to the incomplete filling and inconsistent material flow even with the largest of negative raster gap as shown in Fig. 4.

The part has defects after printing process leading to the errors in dimension and low strength. The printed part is deformed due to the heating and cooling cycle during printing process and under the mechanical load. A definition of the true cross-sectional area of specimen is needed to be considered. The definition of true area contact and the apparent area contact are similar to the terms true stress and engineering stress in mechanic of solid. A model to determine the true cohesive strength between layers is here introduced. The true cohesive strength is evaluated through the calculation of the effective second moment of inertia ratio $(\xi)$.

\subsubsection{The cohesive strength at contact}

The cohesive stress in the bending test

Both three-point and four point-bending tests are used to determine the bending strength of materials. In the three-point bending test, both the shear force and the bending moment contribute to the failure of the specimen. In the four-point-bending test, only the bending moment contributes to its failure.

When the interface between the layers in contact is placed perpendicular to the long axis of the beam, the maximum normal stress calculated in the specimen at failure is the cohesive strength between layers at the true area of contact. The maximum apparent normal 
stress in bending at failure, $\sigma_{z a, y i e l d}$, can be calculated with

$$
\sigma_{z a, y i e l d}=\frac{M_{y i e l d}}{I_{x, C a}} \frac{h}{2}
$$

where $M_{\text {yield }}$ is the value of the internal moment at the mid-point of the beam in the failure region and $h$ is the height of the beam cross section. $I_{x, C a}$ is the apparent second moment of inertia of the cross-section. $I_{x, C a}$ is $b h^{3} / 12$ for the apparent rectangular cross-section area with $b$ being the width of the cross section.

However, in an FDM product, the true cross-section area is a combination of raster by raster contact areas. Therefore, the true second moment of inertia of the cross-section at true contact, $I_{x, C}$, is less than the apparent second moment of inertia, $I_{x, C a}$. Consequently, the ratio between the true second moment of inertia and the apparent second moment of inertia is less than one (The effective second moment of inertia ratio $\xi=\leq 1$ ).

The cohesive strength between layers, therefore, can be calculated as

$$
\sigma_{z, \text { yield }}=\frac{1}{\xi} \sigma_{z a, \text { yield }}=\frac{M_{\text {yield }}}{\xi . I_{x, C a}} \frac{h}{2}
$$

To calculate the cohesive strength between layers, $M_{\text {yield }}$ and $\xi$ have to be determined.

The second moment of inertia and its effective ratio for square contact areas

The true area of contact between two rasters in two layers is shown in Fig. 13 as the transparent colored squares. The true area of contact assumes as the square and the SEM image confirms. The rasters are $90^{\circ}$ apart in successive layers. The distance between 
the two adjacent rasters center line in one layer is determined by

$$
D_{s}=D+g=w+G
$$

where $D$ is raster's width, $g$ is a raster gap, $w$ is a contact width and $G$ is a gap between the two contact areas.

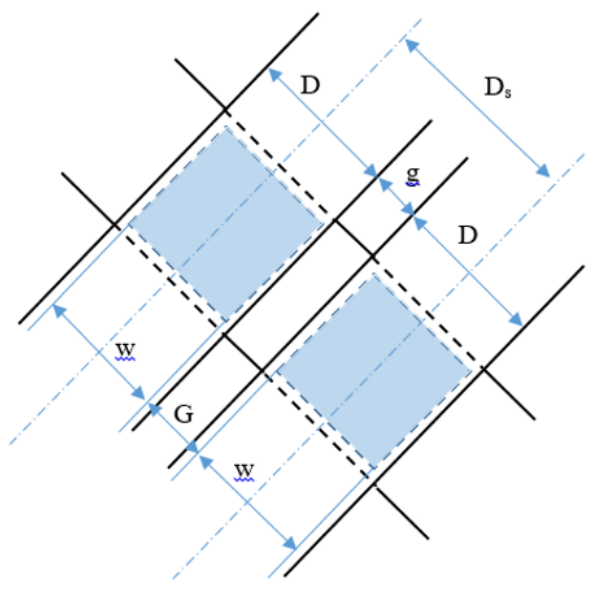

Figure 13: Apparent contact and true contact are.

The raster orientation of $\left[0^{\circ}, 90^{\circ}\right]$ is considered to be the reference orientation. Fig. 14 shows an apparent rectangular cross-section of the bending specimen with the dimensions of $b x h$. The contact areas on the cross-section are considered as a combination of the columns.

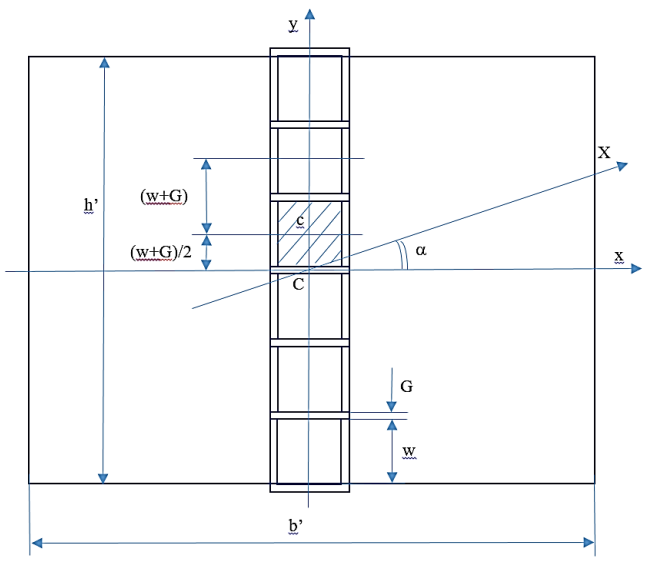

Figure 14: Sketch of two rows of contact with raster orientation of $\left[0^{\circ}, 90^{\circ}\right]$. 
For calculating convenience, the number of contact areas, $N$, in the vertical direction is selected as an even value from the relation $h=N(w+G)=N(D+g)$. The second moment of inertia of an element about axis $C_{x}$ is $I_{x e, c}=w^{4} / 12$, so the second moment of inertia of the first element (hatched element) to the axis $C x$ is calculated by using the parallel axis theorem of mechanics of solids as

$$
I_{x(1), C}=I_{x e, c}+A_{e}\left(\frac{w+G}{2}\right)^{2}
$$

The second moment of inertia of the second adjacent element is

$$
I_{x(2), C}=I_{x e, c}+A_{e}\left(\frac{w+G}{2}+w+G\right)^{2}=I_{x e, c}+A_{e}\left(\frac{w+G}{2}\right)^{2} 3^{2}
$$

The second moment of inertia of the third adjacent element above is

$$
I_{x(3), C}=I_{x e, c}+A_{e}\left(\frac{w+G}{2}\right)^{2} 5^{2}
$$

The second moment of inertia of the whole column $i$ as shown in Fig. 14 is

$$
I_{x(i), C}=2 n I_{x e, C}+2 A_{e}\left(\frac{w+G}{2}\right)^{2} \sum_{j=1}^{n}(2 j-1)^{2}
$$

where $n=N / 2$ and the sum of $1^{2}+3^{2}+5^{2}+\ldots+(2 n-1)^{2}=n\left(4 n^{2}-1\right) / 3$ then

$$
I_{x(i), C}=\frac{n w^{4}}{6}+\frac{w^{4}}{6}(1+\lambda)^{2} n\left(4 n^{2}-1\right)=\frac{n w^{4}}{6}\left[1+(1+\lambda)^{2}\left(4 n^{2}-1\right)\right]
$$

The second moment of inertia of the column about the axis $C_{y}$ is $I_{y i, C}=n \frac{w^{4}}{6}$

Due to $I_{x y 1}=I_{x y 2}=0$, the second moments of inertia of the column $i$ to the axis $C X$ obtained by rotating $C x$ a positive angle $\alpha$ equivalent to change the raster orientation to [ $\alpha$, $\left.\alpha+90^{\circ}\right]$ as shown in Fig. 14 can be calculated as follows: 


$$
\begin{aligned}
& I_{x(i), C}=\frac{I_{x(i), C}+I_{y(i), C}}{2}+\frac{I_{x(i), C}-I_{y(i), C}}{2} \cos 2 \alpha \\
& =\frac{n w^{4}}{6}\left[1+\frac{1}{2}(1+\lambda)^{2}\left(4 n^{2}-1\right)\right]+\frac{n w^{4}}{12}(1+\lambda)^{2}\left(4 n^{2}-1\right) \cos 2 \alpha \\
& I_{X, C}=\frac{n m w^{4}}{6}+\frac{m n w^{4}}{12}(1+\lambda)^{2}\left(4 n^{2}-1\right)(1+\cos 2 \alpha) \\
& =\frac{n m w^{4}}{6}\left[1+(1+\lambda)^{2}\left(4 n^{2}-1\right) \cos ^{2} \alpha\right]
\end{aligned}
$$

For the rectangular cross-section has the length of $\mathrm{b}$ along axis $C X$ and height of $h$. The following relations are derived $h=h^{\prime} \cos \alpha$. The number of row $m$ and the number of column $n$ is

$$
\begin{aligned}
m & =\frac{b \cos \alpha}{(D+g)}=\frac{b \cos \alpha}{D(1+\beta)} ; n=\frac{h^{\prime}}{2(D+g)}=\frac{h}{2 D(1+\beta) \cos \alpha} \\
I_{X, C} & =\frac{b h w^{4}}{12 D^{2}(1+\beta)^{2}}\left[1+\frac{D^{2}}{w^{2}}(1+\beta)^{2}\left(\frac{h^{2}}{D^{2}(1+\beta)^{2} \cos ^{2} \alpha}-1\right) \cos ^{2} \alpha\right] \\
& =\frac{b h^{3} w^{4}}{12 D^{4}(1+\beta)^{2}}\left[\frac{D^{2}}{h^{2}}+\frac{D^{2}}{w^{2}}(1+\beta)^{2}\left(\frac{1}{(1+\beta)^{2} \cos ^{2} \alpha}-\frac{D^{2}}{h^{2}}\right) \cos ^{2} \alpha\right]
\end{aligned}
$$

Introducing the non-dimensional factor $k=D / w$ (ratio of raster width to true raster width), $q=D / h$ (ratio of raster width to the height of the rectangular cross sectional area), and $\gamma=1+\beta=1+\mathrm{g} / \mathrm{D}$, we have

$$
\begin{aligned}
& I_{X, C}=\frac{1}{k^{4} \gamma^{2}}\left[q^{2}+k^{2}-k^{2} \gamma^{2} q^{2} \cos ^{2} \alpha\right] I_{X, C a} \\
& \xi=\frac{1}{k^{4} \gamma^{2}}\left[q^{2}\left(1-k^{2} \gamma^{2} \cos ^{2} \alpha\right)+k^{2}\right]
\end{aligned}
$$

The raster width of $0.508 \mathrm{~mm}$ in was selected for the test so $q=0.508 / 6=0.085$. Substituting the value of $q^{2}=0.0072$ into Eq. (4.2.14) and we have 


$$
\begin{array}{ll}
\alpha=0^{\circ} \text { equivalent to }\left[0^{\circ}, 90^{\circ}\right]: & \xi=\frac{1}{k^{4} \gamma^{2}}\left[0.0072\left(1-k^{2} \gamma^{2}\right)+k^{2}\right] \\
\alpha=15^{\circ} \text { equivalent to }\left[+30^{\circ},-60^{\circ}\right]: & \xi=\frac{1}{k^{4} \gamma^{2}}\left[0.0072\left(1-0.683 k^{2} \gamma^{2}\right)+k^{2}\right] \\
\alpha=45^{\circ} \text { equivalent to }\left[+45^{\circ},-45^{\circ}\right]: & \xi=\frac{1}{k^{4} \gamma^{2}}\left[0.0072\left(1-\frac{1}{2} k^{2} \gamma^{2}\right)+k^{2}\right]
\end{array}
$$

\section{Effective second moment of inertia ratio}

The true width, $w$, of contacts between layers can be measured on the failure crosssection as shown in Fig. 17 for different selected raster gaps. For non-dimensional factor k and $\gamma, D$ is fixed as a constant value of $0.508 \mathrm{~mm}$, the value of $k$ is in the range of $1.176 \leq$ $k \leq 1.5$ corresponding to the measurement of $w$, and the value of $\gamma$ is in the range of $0.85 \leq$ $\gamma \leq 1.15$ corresponding to the range of $g$.

The effective second moment of inertia ratio $\xi$ can be derived from Eq. (4.2.14) in general and from Eq. (4.2.15-4.2.17) for specific considerations with values of $k$ and $\gamma$. The corresponding values of $\xi$ are shown in Table 4 . It is important to note that the second moment of inertia is approximately constant with $\alpha$ in the angle of $0^{\circ}, 15^{\circ}$ and $45^{\circ}$. The influence of angle $\alpha$ and $q$ are therefore negligible. In other words, the first term in the square brackets of the Eq. (4.2.14-4.2.17) can be neglected. The general equation for the second moment of inertia ratio $\xi$ then becomes

$$
\xi \approx \frac{1}{k^{2} \gamma^{2}}
$$


Table 4: Values of the effective second moment of inertia ratio $(\xi)$ corresponding to the raster gap and the true contact width.

\begin{tabular}{|c|c|c|c|c|c|c|c|}
\hline $\begin{array}{c}\text { Raster } \\
\text { gap } \\
(\mathrm{mm})\end{array}$ & $\begin{array}{c}\text { True } \\
\text { contact } \\
\text { width } \\
(\mathrm{mm})\end{array}$ & $\gamma$ & $\mathrm{k}$ & $\begin{array}{c}\xi \\
{\left[+0^{\circ},+90^{\circ}\right]}\end{array}$ & $\begin{array}{c}\xi \\
{\left[+30^{\circ},-60^{\circ}\right]}\end{array}$ & $\begin{array}{c}\xi \\
{\left[+45^{\circ},-45^{\circ}\right]}\end{array}$ & $\begin{array}{c}\xi_{\text {ave }} \\
\end{array}$ \\
\hline-0.025 & 0.4241 & 0.950 & 1.198 & 0.771 & 0.773 & 0.773 & 0.772 \\
\hline 0.000 & 0.3987 & 1.000 & 1.270 & 0.618 & 0.620 & 0.621 & 0.620 \\
\hline+0.025 & 0.3987 & 1.050 & 1.270 & 0.560 & 0.562 & 0.563 & 0.562 \\
\hline+0.050 & 0.3987 & 1.100 & 1.270 & 0.510 & 0.512 & 0.513 & 0.512 \\
\hline
\end{tabular}

Eq. 4.2.18 is plotted in Fig. 15 showing the relation between $\xi$ versus $\gamma$ and $k$ range $(1.176 \leq k \leq 1.5$ and $0.85 \leq \gamma \leq 1.15)$. $\xi$ decreases with the increase of the product of $\gamma^{2}$ and $k^{2}$. The maximum value of $\xi=1$ derived from Eq. (4.2.18) corresponds to the minimum value of $\gamma=0.85$ and $k=1.176$.

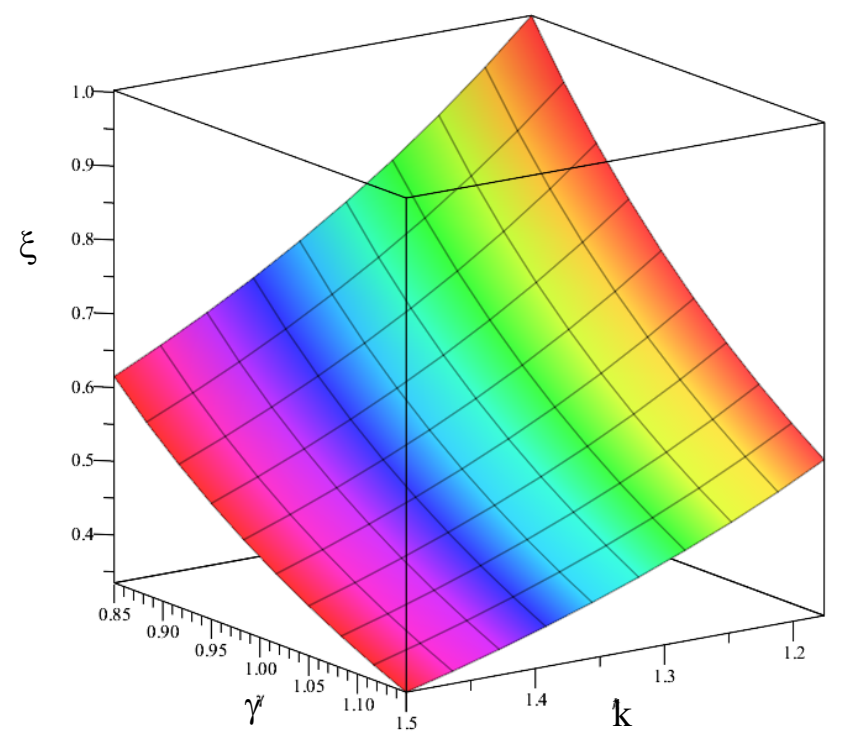

Figure 15: Dependence of the second moment of inertia ratio, $\xi$, on $\gamma$ and $\mathrm{k}$. 


\subsubsection{Determination of cohesive strength between layers at contact}

$P_{\text {yield }}$ is the maximum force recorded at the failure of the specimen. $L '$ is the distance between two supported points of the specimen minus a third of the contact length between the punch and the beam along its length (external force's distribution is approximately a double-triangle along the contact length). Rewriting Eq. (4.2.2) and substituting $L^{\prime}=4.84$ $\mathrm{mm}, h=6 \mathrm{~mm}, b=12 \mathrm{~mm}$ into Eq. (4.2.2), we have

$$
\sigma_{z, \text { yield }}=\frac{3}{2} \frac{P_{\text {yield }} L^{\prime}}{\xi . b h^{2}}=0.017 \frac{P_{\text {yield }}}{\xi} \mathrm{N} / \mathrm{mm} 2
$$

\subsubsection{Experimental procedure and specimen preparation}

The FDM machine used in this study was a Stratasys Fortus 400mc. Nozzle T16 was used to deposit model material and T12 was used to deposit support material. The work material for deposition was polycarbonate (PC) in the form of string with the diameter of $1.77 \mathrm{~mm}$ and $1.80 \mathrm{~mm}$ for support material (SR-100). The raster widths ranged from $0.406 \mathrm{~mm}$ to $0.863 \mathrm{~mm}$. The mini three-point bending apparatus was designed and manufactured at the University of Missouri - Columbia as shown in Fig. 15. Mini threepoint bending tests were carried out on a universal testing machine, ADMET Expert 2600 under quasi-static conditions with a cross-head speed of $5 \mathrm{~mm} / \mathrm{min}$. Scanning electron microscopy (SEM), with a FEI Quanta 600F, was used for image-based analysis in this study.

Polycarbonate blocks were prepared on the Stratasys machine. All printed blocks had dimensions of $60 \times 120 \times 30 \mathrm{~mm}$ and were printed with raster gaps of $-0.025 \mathrm{~mm}, 0.000$ $\mathrm{mm},+0.025 \mathrm{~mm}$, and $+0.050 \mathrm{~mm}$. Raster orientations were $\left[+45^{\circ},-45^{\circ}\right]$ and $\left[+30^{\circ},-60^{\circ}\right]$. 
The raster width was selected as $0.508 \mathrm{~mm}$ and the layer thickness was $0.254 \mathrm{~mm}$. Printed

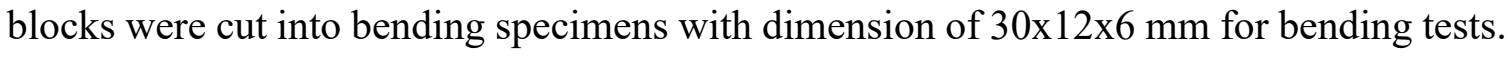
The cross-section area with dimensions of $12 \times 6 \mathrm{~mm}$ of bending specimen were parallel to the layers of original printed block as shown in Fig. 16.

The advantage of this specimen preparation is that the specimens retain the properties of the original blocks without the time it takes to print many small specimens. Moreover, the cohesive strength can be investigated with a bending test at any designed location within a larger build. Specimens are inserted into the die through the horizontal slot and the punch moves into the die through the vertical slot, as shown in Fig. 15. The cross-sectional area, with dimensions of $12 \times 6 \mathrm{~mm}$ on the bending specimen, were parallel to the layers of original printed block and the layer direction was always oriented in the same direction with respect to the bending load in order to separate layers in contact to determine the cohesive strength between layers, as shown in Fig. 16.

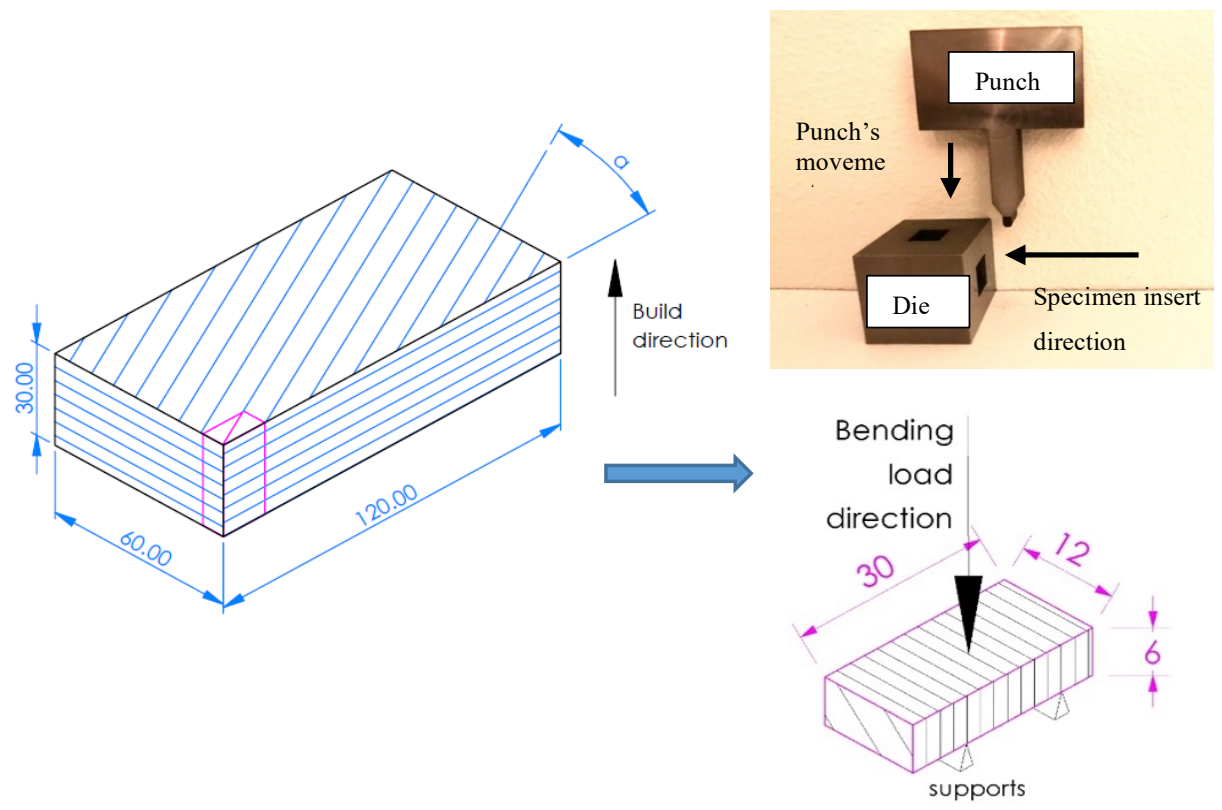

Figure 16: Specimen preparation and the layer orientation with respect to bending load. 


\subsubsection{Results and discussion}

The effective second moment of inertia ratio $\xi$ is a function of four variables, $k, \gamma$, $q, \alpha$, as shown in Eq. (4.2.14). However, from Eq. (4.2.15)- (4.2.17), the dependence of $\xi$ on the raster angle $\alpha$ and $q$ is negligible. Therefore calculations for the most convenient case of the raster orientation $\left[0^{\circ}, 90^{\circ}\right]$ can be used for all different values of $\alpha$, as shown in Eq. (4.2.18). Due to the raster width $D$ selected as a constant, $k$ and $\gamma$ depending on the true width of contacts $w$ and raster gaps $g$ only. In other words, $\xi$ depends on the width of true contact determined by both raster gaps and the nature of the contact's formation.

$\xi$ reached a minimal value of 0.512 corresponding to the raster gap of $+0.050 \mathrm{~mm}$. When a negative raster gap of $-0.025 \mathrm{~mm}$ was applied, the overlap of melt material between two adjacent raster in a layer may cause pushing down of the melt in the overlap region. This leads to a small increase in the contact width resulting in a reduction of $k$ from 1.27 to 1.198 as shown in Table 4. In Fig. 14, $\xi$ increases sharply in the areas where $w$ gets the highest values and $g$ has the lowest values. In other words, $\xi$ depends strongly on the porosity of the FDM product. The porosity can be evaluated by the relative ratio of the density of a printed specimen to the bulk material. The cohesion between two materials at the interface can be stronger than a bulk material. This is entirely consistent with the principle of contact strength stated in tribology.

For a raster angle of $\left[+45^{\circ},-45^{\circ}\right]$, raster gaps varied from $-0.025 \mathrm{~mm}$ to $+0.050 \mathrm{~mm}$. The density ratio change is shown in Table 5. 
Table 5: Density ratio change.

\begin{tabular}{|l|c|c|c|c|}
\hline \multirow{2}{*}{} & \multicolumn{4}{|c|}{ Raster gaps (mm) } \\
\cline { 2 - 5 } & -0.025 & 0.000 & 0.025 & 0.050 \\
\hline Density ratio change & 1 & 0.94 & 0.89 & 0.86 \\
\hline
\end{tabular}

It is clear that the porosity of the FDM products is the main reason for a reduction of up to $14 \%$ of FDM products' density. The effect of convection in the machine chamber may also be taken into account. Moreover, it is evident from Fig. 17 that when the deposited raster is in contact with a previously deposited raster, the contact on the latter side is also softened to form a region of mixing of material resulting in improved bonding in the semimolten state. The weight of the heated filament being extruded seems to have considerable effects on the spreading soften blending material at contact between the two raster under such conditions of softened state and should not be ignored.

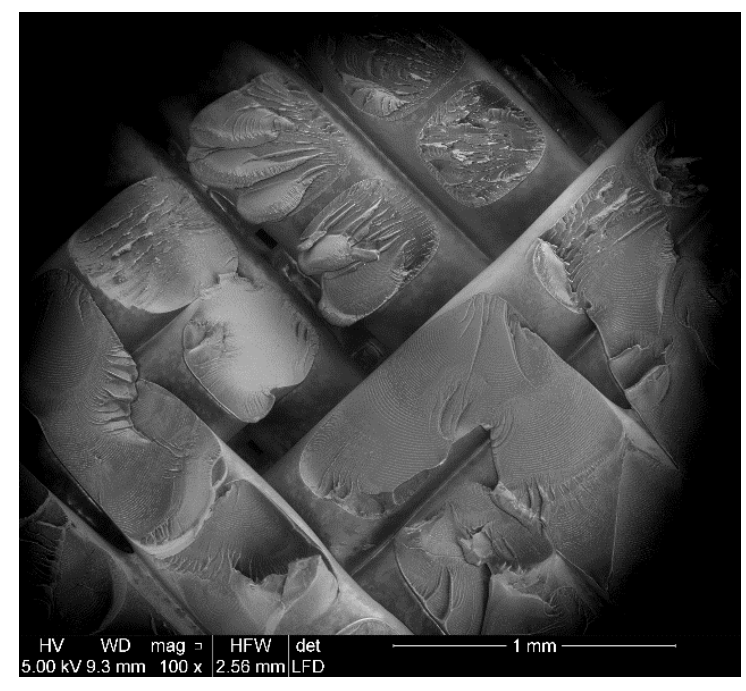

(a) $0.050 \mathrm{~mm}$

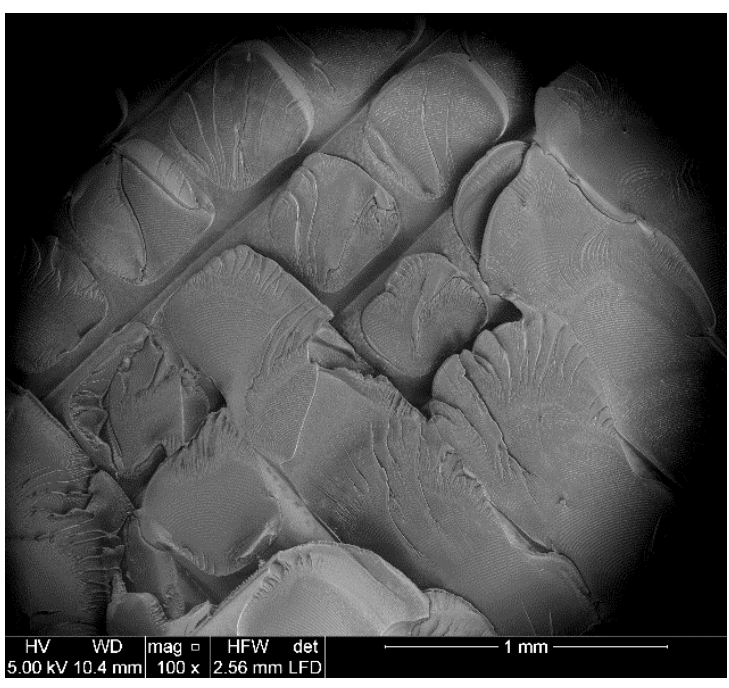

(b) $-0.025 \mathrm{~mm}$

Figure 17: An SEM micrograph showing the contacts between polycarbonate layers in bending test fracture with raster gaps of (a) $0.050 \mathrm{~mm}$ and (b) $-0.025 \mathrm{~mm}$. 
Fig. 18 shows a comparison of the cohesive strength between the material assumed as homogeneous (apparent contact area) and with the model applied (true contact area) for the cases where the raster angles are $\left[+30^{\circ},-60^{\circ}\right]$ and $\left[+45^{\circ},-45^{\circ}\right]$ and the raster gap varies from $-0.025 \mathrm{~mm}$ to $+0.050 \mathrm{~mm}$. For each set of build parameters, three specimens were tested. Table 6 quantitatively shows the standard deviation of each set of build parameters and the whole set. The standard deviation of experimentally determined strength with the model applied in both cases, $\left[+30^{\circ},-60^{\circ}\right]$ and $\left[+45^{\circ},-45^{\circ}\right]$, is smaller than the standard deviation of homogeneous case without the model. This indicates that the data corrected by the model is correctly capturing the part of the variation in the strength due to the geometry of building in FDM printing. The cohesive strength with the true area of contact increasing with increasing of positive raster gaps is a new finding in this study. It emphasizes the considerable difference between strength determined by the apparent crosssection most often described in the literature and the cohesive strength determined by the true area of contact in the apparent cross-section area. 


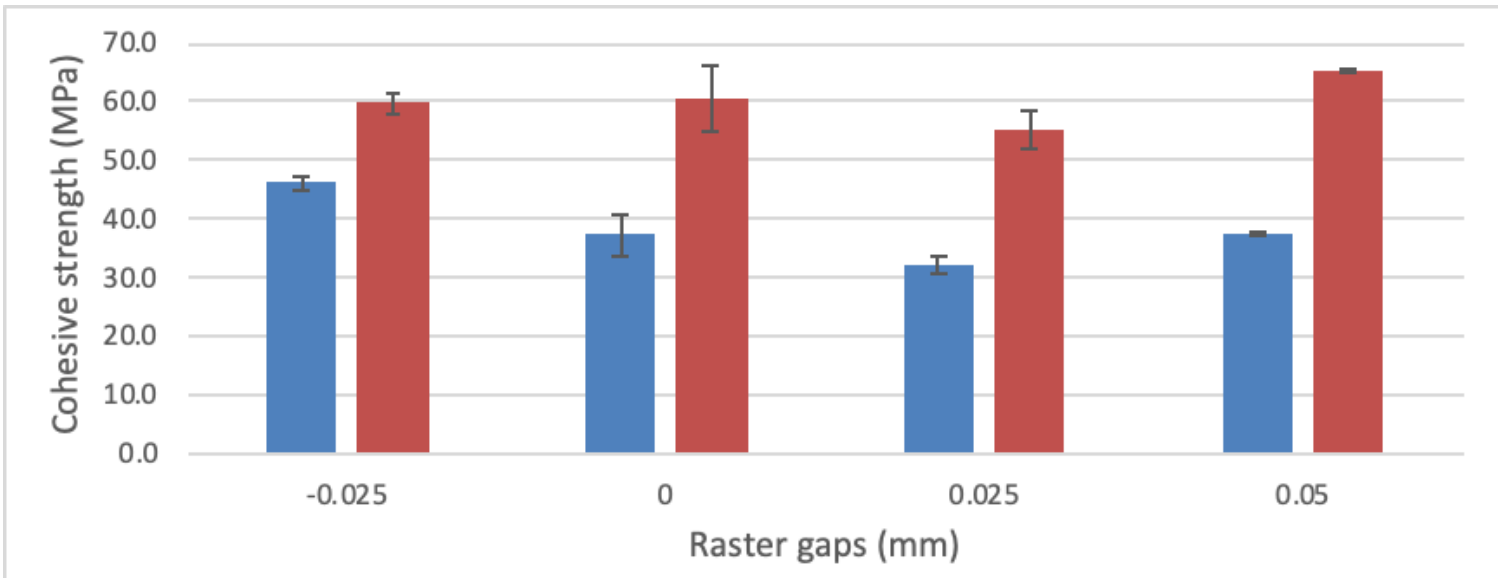

E Apparent strength - Material assumed homogeneus- Raster angle 30

- Cohesive strength - Model applied - Raster angle 30

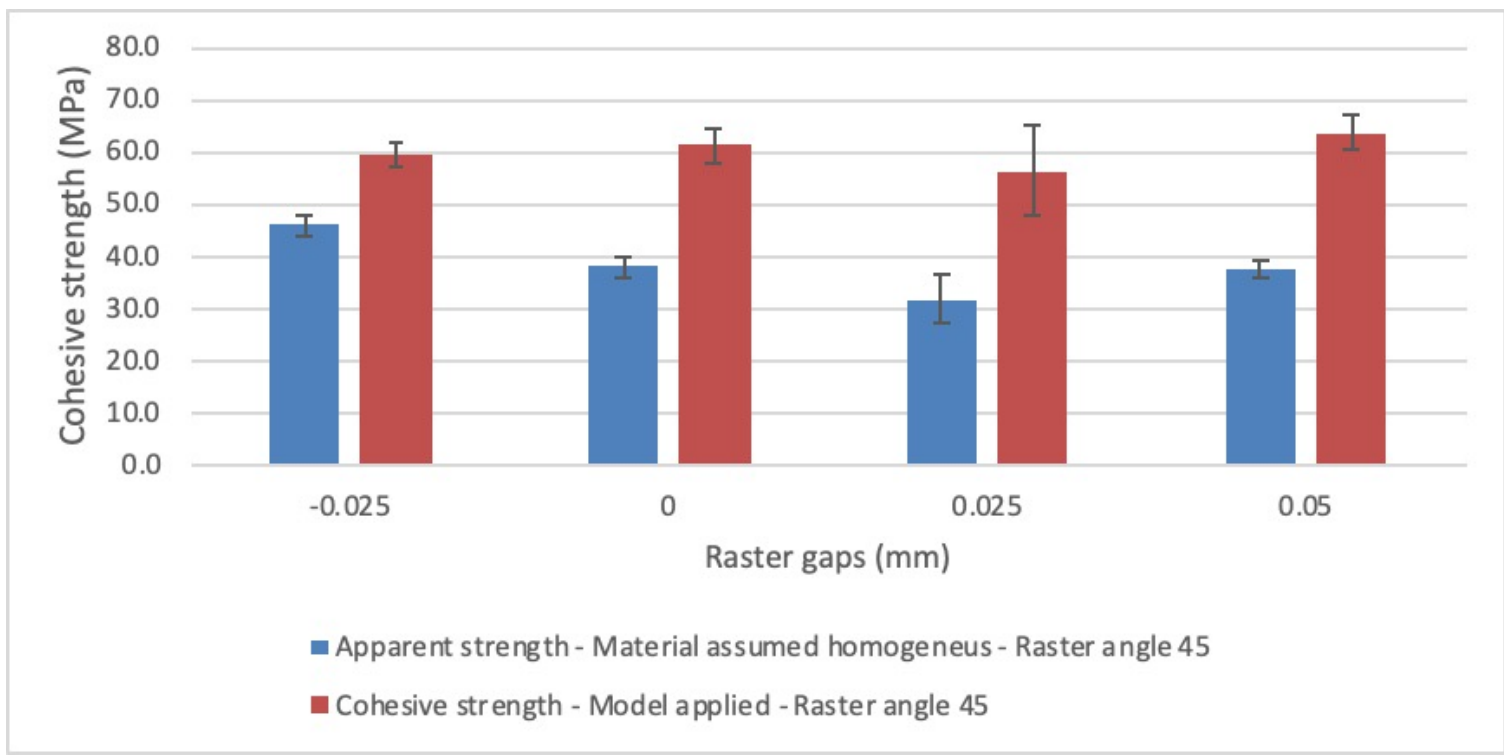

Figure 18: Comparison between material assumed as homogeneous and with the model applied in the cases where the raster angle is $\left[+30^{\circ},-60^{\circ}\right]$ and $\left[+45^{\circ},-45^{\circ}\right]$. 
Table 6: Standard deviation of cohesive strength and the apparent strength.

\begin{tabular}{|c|c|c|c|c|c|c|c|c|}
\hline & \multicolumn{8}{|c|}{ Raster angle $\left[+30^{\circ},-60^{\circ}\right]$} \\
\hline & \multicolumn{4}{|c|}{ Cohesive strength } & \multicolumn{4}{|c|}{ Apparent strength } \\
\hline Raster gap (mm) & -0.025 & 0.000 & 0.025 & 0.005 & -0.025 & 0.000 & 0.025 & 0.005 \\
\hline $\begin{array}{l}\text { St.Dv. of each set of } \\
\text { build parameters } \\
(\mathrm{MPa})\end{array}$ & 1.81 & 5.65 & 3.06 & 0.34 & 1.40 & 3.50 & 1.72 & 0.17 \\
\hline \multirow{3}{*}{$\begin{array}{l}\text { St.Dv. set of raster } \\
\text { angle }\left[+30^{\circ},-60^{\circ}\right] \\
(\mathrm{MPa})\end{array}$} & \multicolumn{4}{|c|}{2.86} & \multicolumn{4}{|c|}{5.47} \\
\hline & \multicolumn{8}{|c|}{ Raster angle $\left[+45^{\circ},-45^{\circ}\right]$} \\
\hline & \multicolumn{4}{|c|}{ Cohesive strength } & \multicolumn{4}{|c|}{ Apparent strength } \\
\hline Raster gap (mm) & -0.025 & 0.000 & 0.025 & 0.005 & -0.025 & 0.000 & 0.025 & 0.005 \\
\hline $\begin{array}{l}\text { St.Dv. of each set of } \\
\text { build parameters } \\
(\mathrm{MPa})\end{array}$ & 2.42 & 3.19 & 8.48 & 3.33 & 1.87 & 1.97 & 4.77 & 1.70 \\
\hline $\begin{array}{l}\text { St.Dv. set of raster } \\
\text { angle }\left[+45^{\circ},-45^{\circ}\right] \\
(\mathrm{MPa})\end{array}$ & \multicolumn{4}{|c|}{2.63} & \multicolumn{4}{|c|}{5.02} \\
\hline
\end{tabular}

A cohesive strength prediction model was introduced. The validation data was taken from mini three-point bending tests. A new way to test the properties of a final part at any designed location and the true contact area for strength determination are also introduced. The future work to be completed is applying the model to other case studies and including the effect of the polymer thermal history into the mechanical properties of the material. 


\subsection{Modeling the effects of heat transfer on the true contact of adjacent rasters}

The apparent contact area and true contact area presented in section 4.1. are evidence that the deposited rasters are well blended with the positive raster gaps. Thermal effects during deposition are one of the reasons to explain the bonding of adjacent rasters. In this section, the modified modeling of the raster deposition of Costa et. al. [44] and sintering $[45,46]$ were used to determine the temperature history during the printing time and further study the effect of thermal mechanisms. Then the corresponded true contact of FDM parts is measured for comparison.

A flowchart of the work is shown in Fig. 19 including five main steps. The first step is determining problems. The second step is identification of the input consisting of part geometry, material properties, FDM process parameters, and the computation parameters. The third step is applying a raster deposition model and a sintering model with an analytical method for computation of the temperature history and the true contact through bond length, respectively. The boundary conditions are updated with time and type of filament contact. The fourth step is doing experiments to measure the true contact of the adjacent rasters. In this step, specimen preparation and ascertaining the effects of parameters are important. The last step is process optimization and performance improvement by revision of any previous steps. 


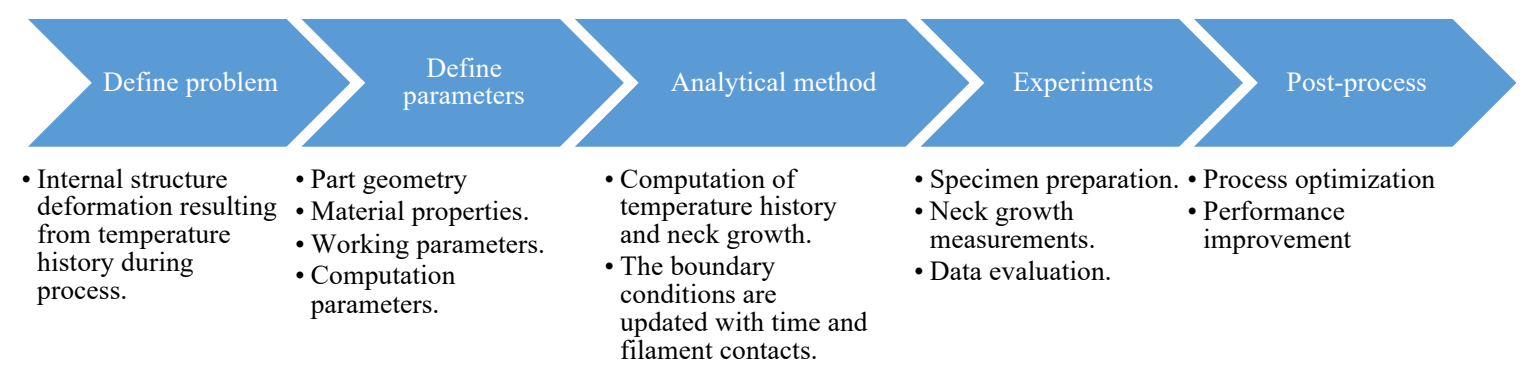

Figure 19: Flowchart of a model to investigate the deformation of FDM printed parts.

During the printing process, a physical contact is created, heat is exchanged by conduction to the support layer and adjacent rasters and convection with the environment when the rasters of the layer are laid down. The more layers that are added, the more physical contacts and heat transfer modes are generated. Moreover, air trapped between adjacent interlayer rasters and intralayer may also develop.

The computational domain of the model is the build chamber including the deposited object as shown in Fig. 20 in gray color. The bottom (build platform) in dark green color has the same temperature as environment temperature. The chamber and the build platform temperature are cooler than the polymer melt temperature. The environment temperature is kept as constant for model simplification. There is convection with environment between deposited raster and the air within the chamber. There is conduction between adjacent deposited rasters or the deposited rasters and the supports. The brown plane presents an arbitrary cross- section plane at general coordinate $x$, on which the temperature history is obtained. 


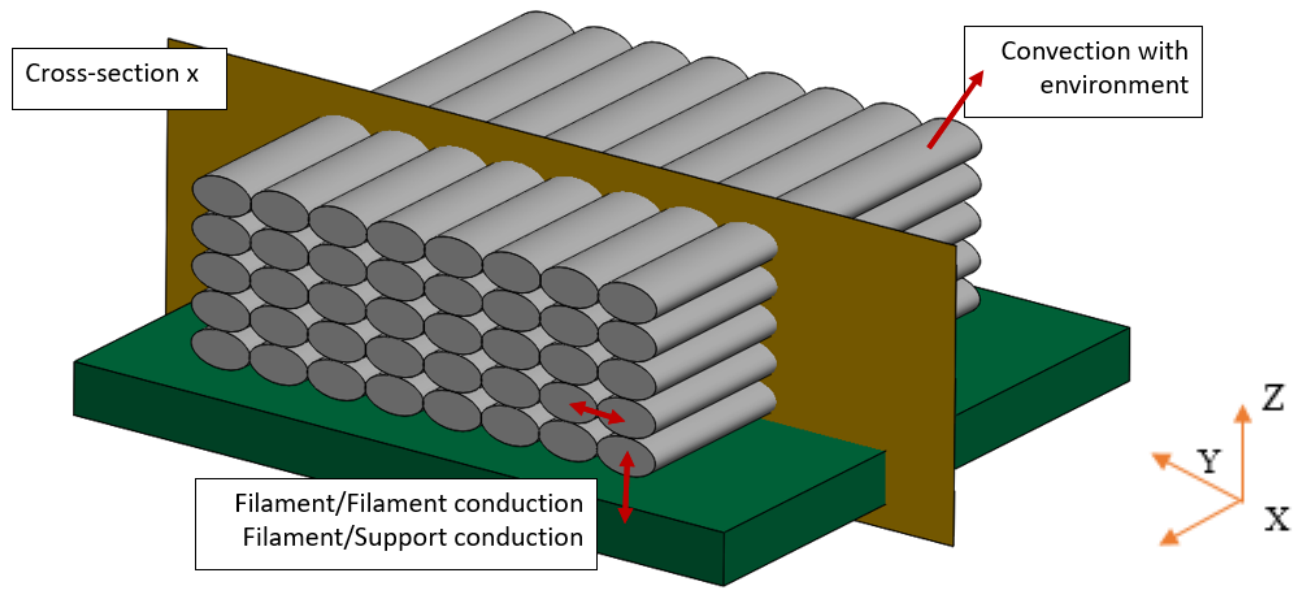

Figure 20: Heat transfer modes and the computational domain for the heat transfer model.

Costa et al. [44] examined the contribution to the overall heat transfer developed during the printing process, including convection and radiation with the environment, conduction with the support and between adjacent rasters, radiation between adjacent rasters, and convection with entrapped air between adjacent rasters. The study shows that radiation with the environment can predominant over convection when the convection coefficient, $\mathrm{h}_{\text {conv }}$, is small or can be negligible when the convection coefficient is large. A convection coefficient value around $60 \mathrm{~W} / \mathrm{m}^{2} \cdot{ }^{\circ} \mathrm{C}$ is used in most practical conditions.

The energy balance in an elementary raster's length $d x$ can be described as $q_{\text {in }}-$ $q_{\text {out }}=\dot{E}_{s t}$. The Costa et. al. model has the assumption of a low thermal conductivity, true for most polymers and a small raster diameter. This assumption is still correct since the Peclet number $\left(\mathrm{P}_{\mathrm{e}}\right)$ is much larger than 1 . Therefore, axial heat conduction can be neglected when compared to the remaining terms and the energy equation can be written as 


$$
\begin{aligned}
\frac{\partial T_{r}}{\partial t}=-\frac{P}{\rho C A}( & h_{\text {conv }}\left(1-\sum_{i=1}^{n} a_{r i} \lambda_{i}\right)\left(T_{r(x, t)}-T_{\infty}\right) \\
& \left.+\sum_{i=1}^{n} h_{\text {cond }} a_{r i} \lambda_{i}\left(T_{r(x, t)}-T_{r i}\right)\right)
\end{aligned}
$$

where $P$ is the raster perimeter $(m)$ of the raster with the elliptical cross-section given by [47]

$$
P=\Pi(a+b)\left(1+\frac{3 h}{10+\sqrt{4-3 \frac{(a-b)^{2}}{(a+b)^{2}}}}\right)
$$

$\lambda_{i}$ is the fraction of perimeter that is in contact with another segment or support (i.e the percentage overlap due to the printing setting). Variable $a_{r i}$ is defined, referring to Fig. 21, as [11]

$$
a_{r i}=\left\{\begin{array}{c}
1 \text { if the } r^{\text {th }} \text { filament has } i^{\text {th }} \text { contact } \\
0 \text { otherwise } \\
\forall i \in(1, \ldots, n), \forall r \in(1, \ldots N)
\end{array}\right.
$$

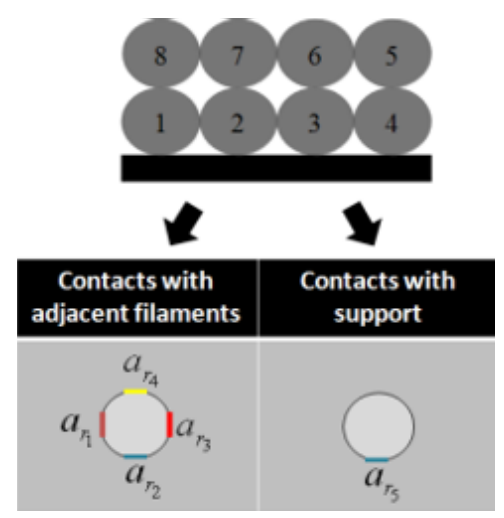

Figure 21: Type of contact in a raster for the heat transfer model. 
The raster temperature as a function of time can be solved by the characteristic polynomial method as [11]

$$
\begin{aligned}
T_{r}(t)=\left(T_{r 0}-\right. & \left.Q\left(a_{r 1}, \ldots, a_{r n}\right)\right) e^{\frac{-P L b\left(a_{r 1}, \ldots, a_{r n}\right)\left(t-t_{r}\right)}{\rho V C}} \\
& +Q\left(a_{r 1}, \ldots, a_{r n}\right)
\end{aligned}
$$

where $t_{r}$ is the instant at which the $r$-th filament starts to cool down or contact another raster, $T_{r 0}=T_{r}\left(t_{r}\right)$ is the temperature of the filament at instant $t_{r} . b$ and $Q$ are

$$
\begin{array}{r}
b\left(a_{r 1}, \ldots, a_{r n}\right)=h_{\text {conv }}\left(1-\sum_{i=1}^{n} a_{r i} \lambda_{i}\right)+\sum_{i=1}^{n} a_{r i} h_{i} \lambda_{i} \\
Q\left(a_{r 1}, \ldots, a_{r n}\right)=\frac{h_{c o n v}\left(1-\sum_{i=1}^{n} a_{r i} \lambda_{i}\right)+\sum_{i=1}^{n} a_{r i} h_{i} \lambda_{i}}{b\left(a_{r 1}, \ldots, a_{r n}\right)}
\end{array}
$$

The assumptions of a uniform temperature at each cross-section area in a raster are valid if $B i \leq 0.1(B i=0.0780)$. The Biot number can be defined as a function of part geometry and contact relation [48].

$$
B_{i}=\frac{A}{P} \frac{b\left(a_{r 1}, \ldots, a_{r n}\right)}{k}
$$

The Stratasys production system $400 \mathrm{mc}$ was used in this study with the dimensions of its building box being $355.6 \times 355.6 \times 406.4 \mathrm{~mm}(14 \times 14 \times 16$ inches $)$. The initial temperature was set as the nozzle temperature $\left(325^{\circ} \mathrm{C}\right)$, the final temperature (ambient temperature) is the chamber temperature $\left(130{ }^{\circ} \mathrm{C}\right)$ as the default setting of the FDM machine. These temperatures are the initial temperature boundary and final temperature boundary. The internal air is forced out so that a negative air pressure is created pulling air passively into the system from the other inlets. In the FDM process, the three different states, (i) fully solid, (ii) high elastic and (iii) semi-molten liquid, are present as the 
temperature increases. The polymer leaving the nozzle is in the semi-molten liquid state at a temperature above the solidus point (melting of a substance begins), the typical nozzle temperature of $325^{\circ} \mathrm{C}$ for PC filament. PC filament has a glass transition temperature of about $147{ }^{\circ} \mathrm{C}$, so it softens gradually above this point and flows above about $155^{\circ} \mathrm{C}$. When the temperature decreases to the solidus point the viscosity increases dramatically. As the temperature drops further down to the glass transition point, about $147^{\circ} \mathrm{C}$, the viscosity becomes very large, making the polymer rigid. Additionally, the enthalpy and volume of the injected material will change with its microscopic organization when the temperature crosses a phase-transition point.

The default extrusion tip was used with a raster width of $5.08 \times 10^{-4} \mathrm{~m}(0.02 \mathrm{in})$ and a layer thickness of $2.54 \times 10^{-4} \mathrm{~m}(0.01 \mathrm{in})$. The cylindrical geometry of the extrusion tip and 2:1 width to height proportions (from raster width and layer thickness given) produces an elliptical cross-section. Thus, the cross-section of the filament was modeled as an ellipse. The fraction factor was 0.25 (Eq. 4.3.2) [44].

The filament material used in the study was polycarbonate (PC). PC is an amorphous thermoplastic that consists of macromolecule chains with no crosslinking between the chains, as shown in Fig. 22 [49] . In general, it is optically transparent and relatively strong. The properties of polycarbonate are shown in Table 7 [50]. The thermal conductivity changes in range of $0.21-0.24$ between the temperature of $130^{\circ} \mathrm{C}$ and $325^{\circ} \mathrm{C}$. The thermal conductivity was kept constant at a value of 0.21 as an assumption of the model. 


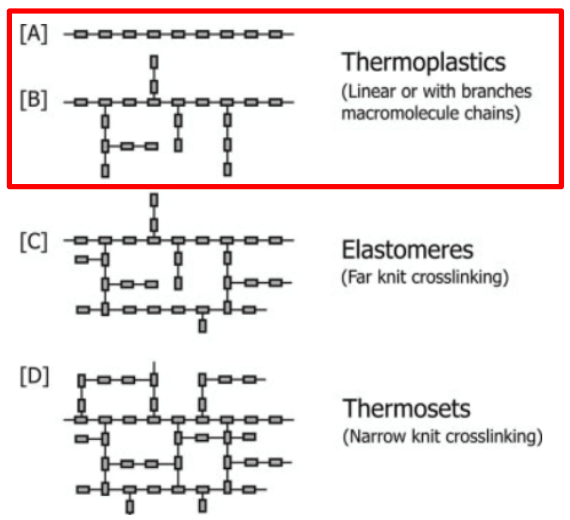

Figure 22: Principle of structure of thermal plastic.

Table 7: Polycarbonate (PC) properties used in the study.

\begin{tabular}{|l|c|}
\hline \multicolumn{1}{|c|}{ Property } & Value \\
\hline Density of the polymer, $\rho_{\mathrm{p}}\left(\mathrm{kg} / \mathrm{m}^{3}\right)$ & 1200 \\
\hline Thermal conductivity of the polymer, $\mathrm{k}_{\mathrm{p}}(\mathrm{W} / \mathrm{m} \cdot \mathrm{K})$ & 0.21 \\
\hline Specific heat capacity of the polymer, $\mathrm{C}_{\mathrm{p}, \mathrm{p}}(\mathrm{J} / \mathrm{kg} \cdot \mathrm{K})$ & 1200 \\
\hline Glass temperature $\left({ }^{\circ} \mathrm{C}\right)$ & $145^{\circ} \mathrm{C}$ \\
\hline Heat transfer convection coefficient $\left(\mathrm{W} / \mathrm{m}^{2} \cdot \mathrm{C}\right)$ & 60 \\
\hline Thermal contact conductance $\left(\mathrm{W} / \mathrm{m}^{2} \cdot{ }^{\circ} \mathrm{C}\right)$ & 70 \\
\hline
\end{tabular}

A Matlab program was used for computation. The program input was part geometry, material properties, FDM process parameters, and the computation parameters. The Costa et al. analytical model was used for computation of the temperature history. The boundary conditions were updated with time and types of contact. The temperature of each raster as a function of time and location of the cross-section, $\mathrm{x}$, was calculated simultaneously. 
The length of each deposited raster is $0.7 \mathrm{~m}$. The cross-section $x$ is at $0.35 \mathrm{~m}$. Fig. 23 shows the part geometry in isotropic view and the front view of the one-layer part as an example. The corresponding temperature history of the one-layer part is shown in Fig. 24. The temperature of the deposited raster cools down and then increases when a newly deposited raster is placed adjacent to a priorly deposited raster as shown in Fig. 24. The high temperature from a newly deposited raster is transferred to the priorly deposited raster and raises its temperature. Moreover, a higher heat transfer convection coefficient leads to an increasing cooling rate. In this work, the heat transfer convention coefficient was chosen to have a value most common in practical uses as $60 \mathrm{~W} / \mathrm{m}^{2} \cdot{ }^{\circ} \mathrm{C}$. The fraction factor also has an effectiveness on the temperature history. The higher the fraction factor the easier the heat transfer between adjacent rasters is.
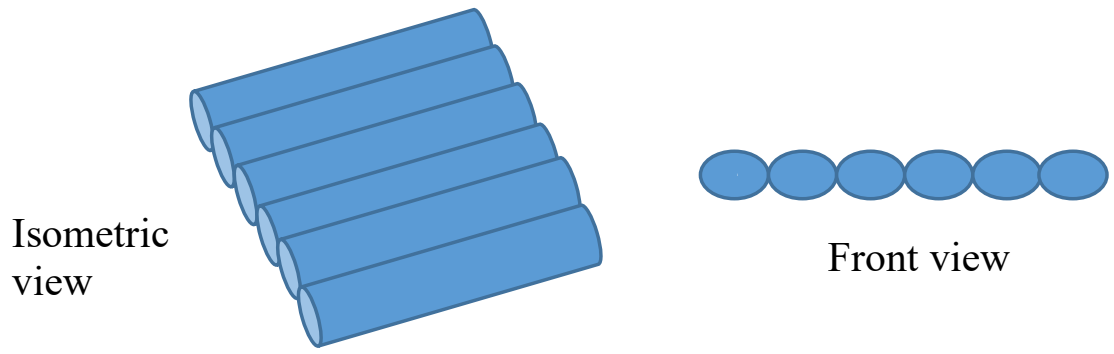

Front view

Figure 23: Part geometry used in the modelling work. 


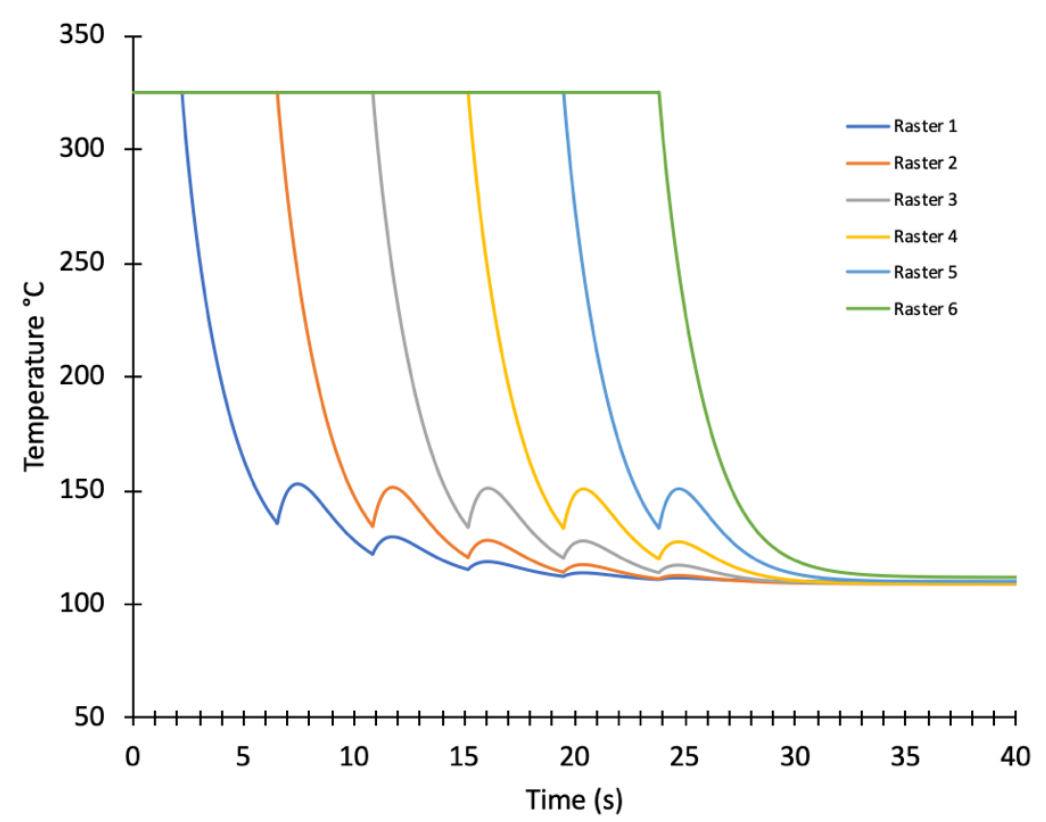

Figure 24: Temperature history of printed part.

A bonding model proposed by Gurrala et. al. and Regalla et al. $[45,46]$ uses the concept of neck growth between adjacent rasters. The purpose of the concept is predicting the neck growth also called bond length. As shown in Fig. 25, $\mathrm{r}_{\mathrm{o}}$ is the initial radius of the cross-sectional area of a deposited raster. The neck growth half-length $(y)$ is equal to

$$
y=r \sin \theta
$$

where $\theta$ is half of the neck growth angle and $r$ is the final radius of the cross-sectional area of a deposited raster. 


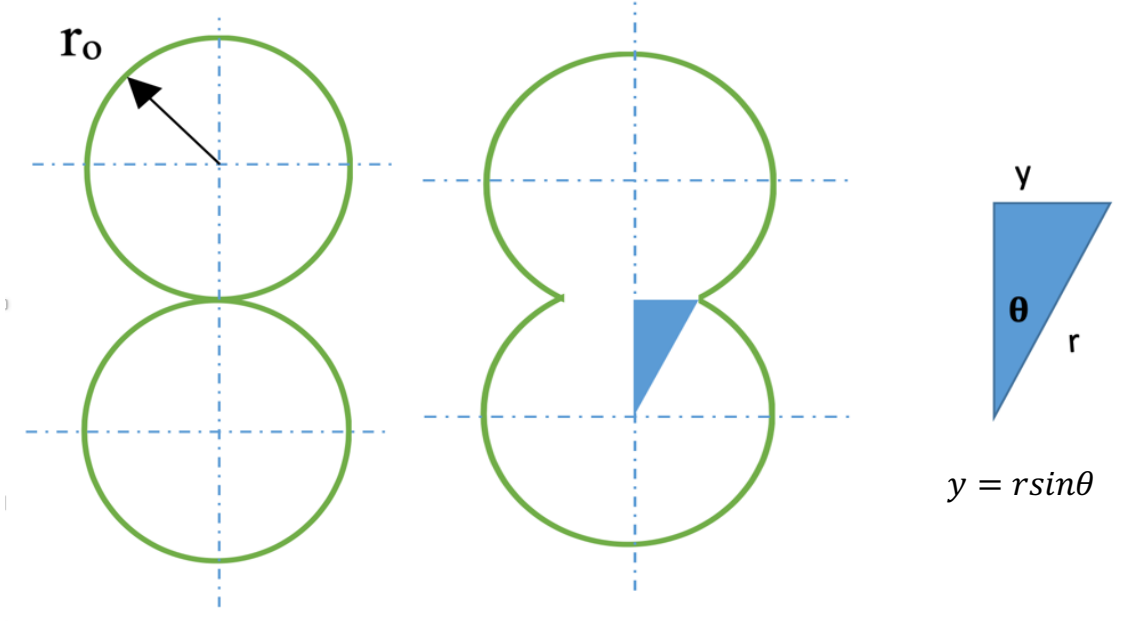

Figure 25: Neck growth evolution.

The work of surface tension on adjacent rasters under the influence of surface tension is given as

$$
\begin{aligned}
& W_{s}=-\Gamma \frac{d S}{d t} \\
& S=2 \operatorname{lr} \sin \theta \\
& r=\frac{r_{o} \pi}{\sqrt{\pi-\theta+\sin \theta \cos \theta}}
\end{aligned}
$$

where $\Gamma$ is the coefficient of surface tension, $S$ is the instantaneous cross-sectional area at time $t$.

The work of viscous forces is

$$
W_{v}=6 \pi r_{o}^{2} \ln \frac{(\pi-\theta)^{2} \sin ^{2} \theta}{(\pi-\theta+\sin \theta \cos \theta)^{2}} \dot{\theta}^{2}
$$

With the assumption of equating the work of surface tension to the work of viscous forces of the sintering system, the rate of change of the neck growth is 


$$
\frac{d \theta}{d t}=\frac{\Gamma t}{3 \sqrt{\pi} r_{o} \eta} \frac{[(\pi-\theta) \cos \theta+\sin \theta][\pi-\theta+\sin \theta \cos \theta]^{1 / 2}}{(\pi-\theta)^{2} \sin ^{2} \theta}
$$

where

$$
\eta=\eta_{r} \exp \left(-0.01\left(T-T_{r}\right)\right)
$$

The neck growth half-length in Eq. (4.3.7) using as the viscosity in Eq. (4.3.12) is as the function of temperature as shown in Eq. (4.3.13). Eq. (4.3.12) was solved using the $4^{\text {th }}$ order of Runge-Kutta method. The temperature history at the cross-section at $x$ of the raster from the Costa et. al. model was embedded into Eq. (4.3.13) for viscosity calculation as a function of temperature. When the temperature decreases to the solidus point the viscosity increases dramatically. As the temperature drops further down to the glass transition point, about $147^{\circ} \mathrm{C}$, the viscosity becomes very large, making the polymer rigid [51] as shown in Fig. 26.

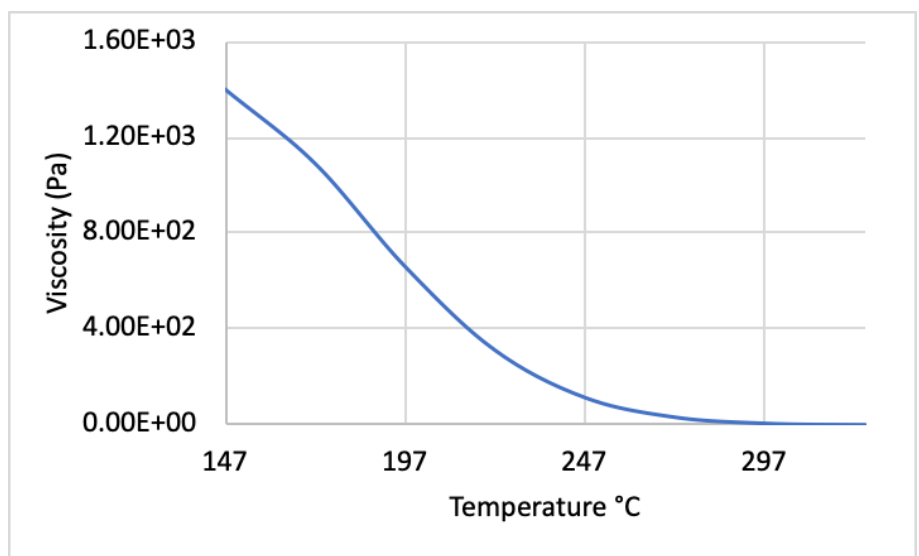

Figure 26: Viscosity as a function of temperature.

The neck growth mechanics during the sintering process are active from the initial temperature of $325^{\circ} \mathrm{C}$ to the temperature above glass transition temperature of $147^{\circ} \mathrm{C}$. This corresponds to a time constant of $\sim 8$ seconds, as shown in the temperature history of 
the deposited raster in Fig. 24. Moreover, Fig. 27 shows the temperature history of the deposited raster using different values for the fraction of perimeter. The similarity of temperature history for different values of fraction of perimeter suggests that the temperature history is insensitive to the conduction conditions. Furthermore, Fig. 28 shows a prediction of the evolution of the neck growth with time using different values of fraction of perimeter in the temperature modelling. The prediction of neck growth changes with a time constant of $\sim 4$ seconds. The prediction of neck growth was computed using a single value of conduction conditions to neighboring rasters even though the neck growth changes those conduction conditions. The prediction of neck growth and temperature histories are all almost the same with different values of fraction perimeter as shown in Fig. 27 and Fig. 28 which shows that the evolution of neck growth is insensitive to changes in the conduction conditions and that convection is dominating the heat flow and the temperature.

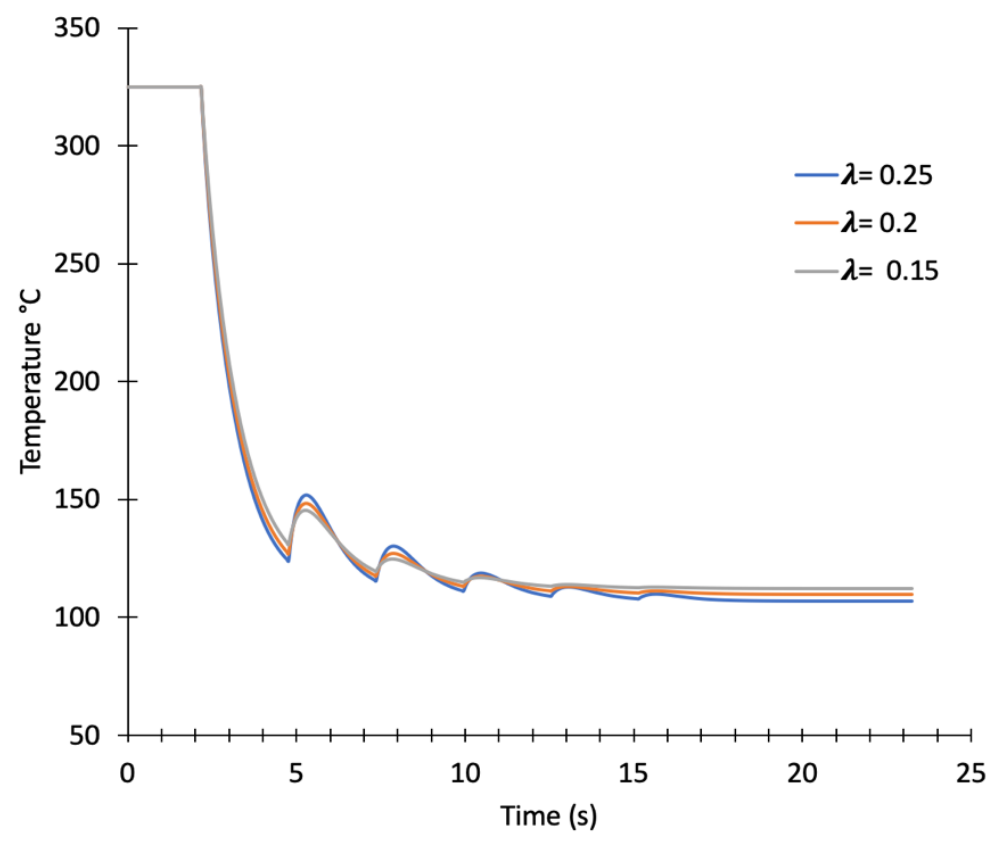

Figure 27: Temperature history of deposited raster with different value of fraction of perimeter. 


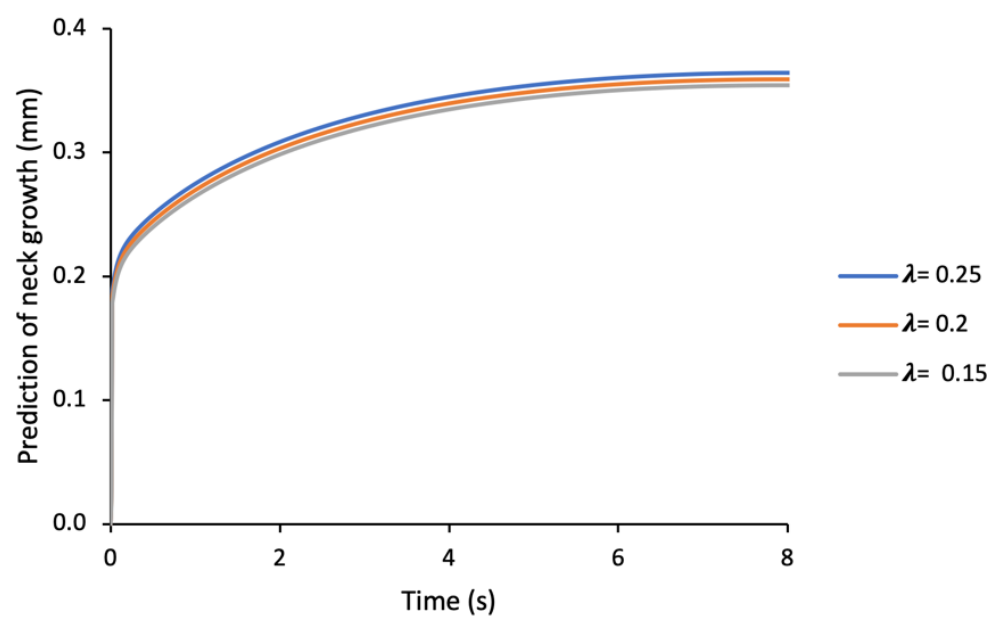

Figure 28: Evolution of neck growth with time.

Fig. 29 shows the true contact area of adjacent rasters with the raster gap of 0.000 $\mathrm{mm}$ and three different raster angles of $\left[0^{\circ}, 0^{\circ}\right],\left[+45^{\circ},-45^{\circ}\right]$ and $\left[+30^{\circ},-60^{\circ}\right]$. A measure of the true contact was taken three times and then averaged. Table 8 shows the quantitative comparison of the measured true contact and the predicted neck growth length. The error in the predicted neck growth of the raster angle of $\left[0^{\circ}, 0^{\circ}\right]$ compared to the measured value is $7.9 \%$. The error in the predicted neck growth of the raster angle of $\left[+45^{\circ},-45^{\circ}\right]$ compared to the measured value is $13.8 \%$. The error in the predicted neck growth of the raster angle of $\left[+30^{\circ},-60^{\circ}\right]$ compared to the measured value is $5.5 \%$. The raster angle which is not included in the modelling leads to the differences in the error.

The errors in the predictions most likely come from:

(1) the assumption in the relevant heat transfer of negligible thermal radiation between the deposited rasters and the environment;

(2) the properties of the printed material (density, specific heat, thermal conductivity, surface tension coefficient) are not know with certainty and are treated as a constants; 
(3) the raster gap of 0.000 is kept constant and the raster angle is not included in the modeling.

(4) gravitational force is not included in the modeling;

(5) the diffusion of polymer chains across the raster interface is not included.

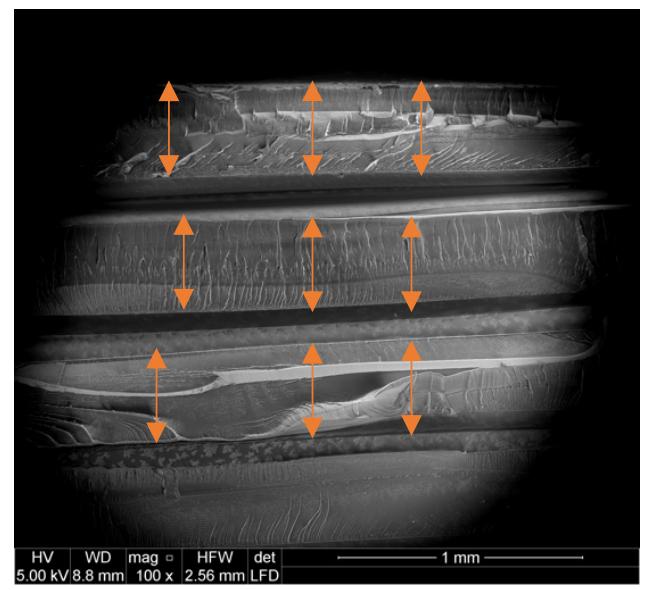

(a) $\left[0^{\circ}, 0^{\circ}\right], 0.000 \mathrm{~mm}$

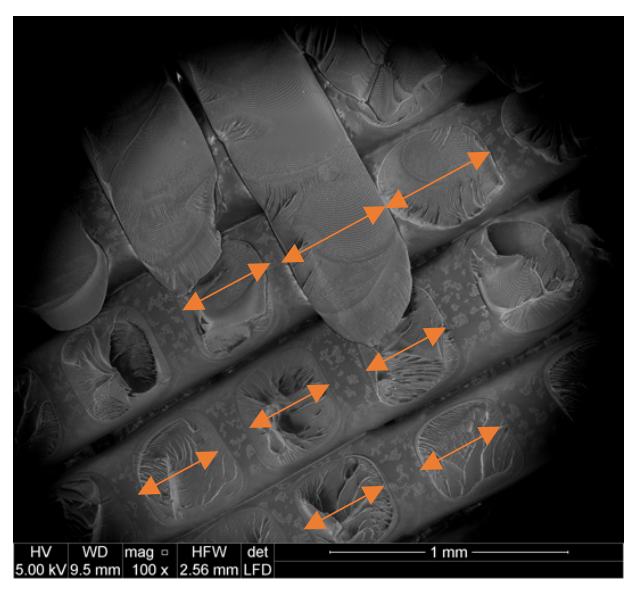

(c) $\left[+30^{\circ},-60^{\circ}\right], 0.000 \mathrm{~mm}$

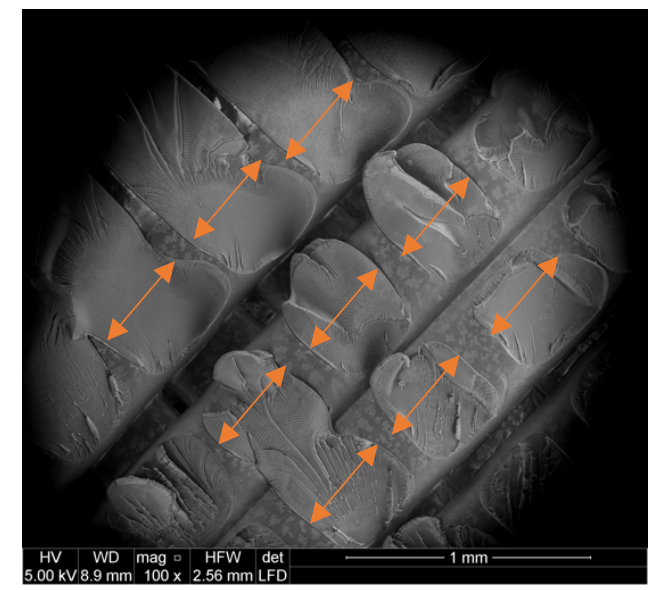

(b) $\left[+45^{\circ},-45^{\circ}\right], 0.000 \mathrm{~mm}$

Figure 29: Measurements of the true contact of adjacent rasters (a) $\left[0^{\circ}, 0^{\circ}\right], 0.000 \mathrm{~mm}$ (b) $\left[+45^{\circ},-45^{\circ}\right], 0.000 \mathrm{~mm},(\mathrm{c})\left[+30^{\circ},-60^{\circ}\right], 0.000 \mathrm{~mm}$. 
Table 8: Comparison of the measured and the predicted bond lengths.

\begin{tabular}{|c|c|c|c|c|}
\hline $\begin{array}{l}\text { Raster gaps } \\
(\mathrm{mm})\end{array}$ & Raster angle $\left(^{\circ}\right)$ & Measured true contact $(\mathrm{mm})$ & $\begin{array}{c}\text { Prediction } \\
(\mathrm{mm})\end{array}$ & \% Error \\
\hline 0.000 & {$\left[0^{\circ}, 0^{\circ}\right]$} & 0.39 & 0.36 & +7.9 \\
\hline 0.000 & {$\left[+45^{\circ},-45^{\circ}\right]$} & 0.41 & 0.36 & +13.8 \\
\hline 0.000 & {$\left[+30^{\circ},-60^{\circ}\right]$} & 0.38 & 0.36 & +5.5 \\
\hline
\end{tabular}

This work shows a better understanding of the temperature history's effect on the behavior of $3 \mathrm{D}$ printed parts. It is feasible to successfully predict the overall strength of printed parts by a combination of mechanical and thermal modelling. For the thermal model, accurate determination of the relevant heat transfer of the modes and heat transfer coefficients are needed. With these models, a robust and reliable additive manufacturing process can be further developed which reaches a higher performance in the application.

\section{Conclusions}

Fused deposition modeling (FDM) is a technique used to build rapid prototypes out of thermoplastic materials. Printing technology continues to mature from a rapid prototyping process to a rapid manufacturing technique, therefore predicting the behavior of printed parts has become increasingly desirable. This study aims to determine the relations between process parameters, including temperature history and the strength and deformation of the internal structure of printed parts.

The first part of the current work presented studies of the properties of printed parts by using DOE (design of experiments). The mechanical properties of FDM printed parts in two studies (tensile and bending) show the influence of the working parameters (raster 
gaps, raster angles, layer thickness) on the properties of parts. The most significant distribution factor is the raster gaps, the intermediate factor is the raster angle and the layer thickness has the least distribution on the properties of printed parts. From these studies, the raster gaps and raster angles are the interesting factors for further study in the last two parts. The analysis results can be developed into an optimization problem in design and production. The extrusion velocity and raster velocity should be involved in future work studying the influence of process parameters on the mechanical properties of FDM parts.

Through observation and data analysis in a DOE approach, it is interesting to see that adjacent rasters are well blended even for zero and positive values of the raster gap. The marks of successively deposited rasters left on an adjacent raster is evidence of the true contact area. Development of a combined analytical and experimental approach for the determination of the cohesive strength between layers, taking into account the true contact area in order to better understand the cohesion between layers, was introduced and was verified qualitatively with bending experiments. Also, a new method of mechanical properties testing with small bending test specimens was developed.

The use of heat transfer and sintering models in the third part shows the effectiveness of time-dependent temperature on the true contact between adjacent rasters on an FDM part. The comparison of measured data and predictions is reasonably good but unable to achieve $95 \%$ accuracy. This demonstrates the need to accurately determine the temperature-dependent material properties, the relevant heat transfer of the modes and the heat transfer coefficients in future work. 
The current work, while not achieving a prediction with the temperature history effect within $5 \%$, does provide a significant improved in the understanding of the properties of printed parts. However, an improved model, addressing the issues listed above, promises to improve the accuracy of the predicted properties of 3D printed parts. This capability will help to promote FDM as a robust and reliable additive manufacturing process.

\section{APPENDIX}

\section{A. Calculation of cohesive strength between layers at contact}

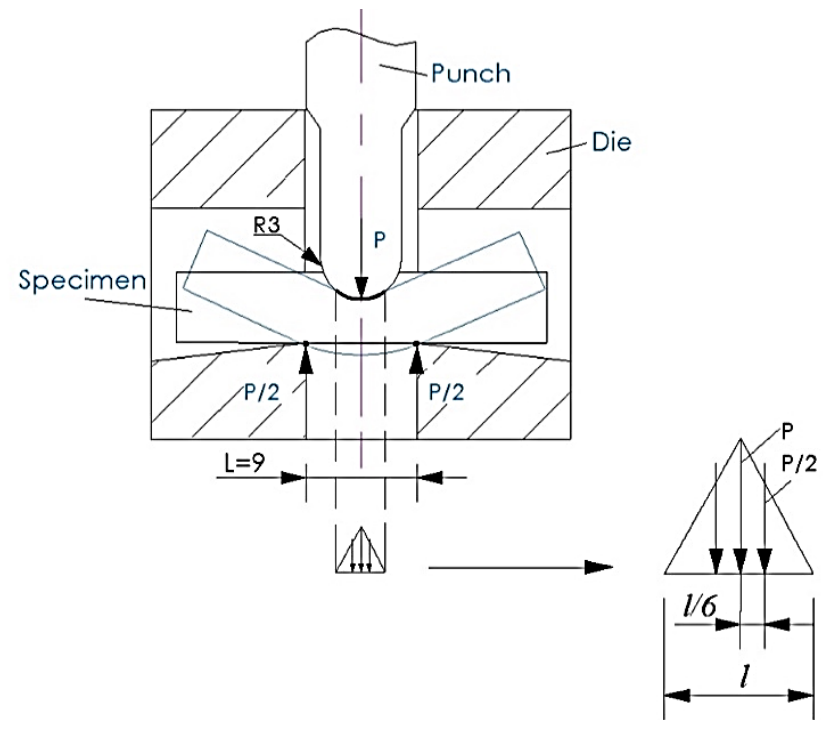

The diameter of the punch head is $6 \mathrm{~mm}$ and the distance between two supports is $9 \mathrm{~mm}$. Therefore, the punch and specimen contact is considered as arc contact instead of point contact. The punch force acting on arc contact are illustrated by force diagram for simplifier in calculation. From Eq. (4.2.2) 


$$
\begin{array}{r}
\sigma_{z, \text { yield }}=\frac{1}{\xi} \sigma_{z a, y i e l d}=\frac{M_{\text {yield }}}{\xi \cdot I_{x, \text { Ca }}} \frac{h}{2}=\frac{\frac{P}{2} \cdot \frac{L}{2}-\frac{P}{2} \cdot\left(\frac{1}{3} \cdot \frac{l}{2}\right)}{\xi \cdot \frac{b h^{3}}{12}} \cdot \frac{h}{2} \\
=\frac{\frac{P}{4} \cdot\left(L-\frac{l}{3}\right)}{\xi \cdot \frac{b h^{3}}{12}} \cdot \frac{h}{2}=\frac{\frac{P}{4} \cdot L^{\prime}}{\xi \cdot \frac{b h^{3}}{12}} \cdot \frac{h}{2}=\frac{3}{2} \cdot \frac{P_{y i e l d} \cdot L^{\prime}}{\xi \cdot b h^{2}}
\end{array}
$$

$L^{\prime}$ is the distance between two supported points of the specimen minus a third of the contact length between the punch and the specimen along its length. Substitute value of $L^{\prime}=4.84$ $m m, h=6 \mathrm{~mm}, b=12 \mathrm{~mm}$, have Eq. (4.2.19)

$$
\sigma_{z, \text { yield }}=\frac{3}{2} \frac{P_{y i e l d} L^{\prime}}{\xi \cdot b h^{2}}=0.017 \frac{P_{y i e l d}}{\xi} \mathrm{N} / \mathrm{mm}^{2}
$$

\section{B.1. Temperature history of filament during printing process}

Energy balance for an elementary length $d x: q_{\text {in }}-q_{\text {out }}=\dot{E}_{s t}$

The energy in at one face

$$
q_{i n}=-k A \frac{\partial T_{r(x, t)}}{\partial x}
$$

The energy out the differential element

$$
q_{\text {out }}=-A\left(k \frac{\partial T_{r(x, t)}}{\partial x}+\frac{\partial\left(k \frac{\partial T_{r(x, t)}}{\partial x}\right)}{\partial x} d x\right)
$$

Loss of heat transfer by convection

$$
Q_{\text {conv }}=h_{\text {conv }} \cdot A_{\text {conv }} \cdot\left(T_{r(x, t)}-T_{E}\right)
$$

where $A_{c o n v}$ is cross-sectional area of contact length between the filament and the foundation 
Loss of heat transfer by conduction

$$
Q_{\text {cond }}=\sum_{i=1}^{n} h_{\text {cond }} \cdot A_{\text {cond }} \cdot\left(T_{r(x, t)}-T_{r i}\right)
$$

The change of the internal energy of the element

$$
\frac{E_{s t}}{\partial t}=\rho C A \frac{\partial T_{r(x, t)}}{\partial t} d x
$$

Energy balance on the element $d x$

$$
\begin{aligned}
& q_{\text {in }}-q_{\text {out }}=\dot{E}_{\text {st }} \\
& \rightarrow-k A \frac{\partial T_{r(x, t)}}{\partial x}-h_{\text {conv }} \cdot A_{\text {conv }} \cdot\left(T_{r(x, t)}-T_{E}\right)-\sum_{i=1}^{n} h_{\text {cond }} \cdot A_{\text {cond }}\left(T_{r(x, t)}-T_{r i}\right) \\
& \quad=-A\left(k \frac{\partial T_{r(x, t)}}{\partial x}+\frac{\partial\left(k \frac{\partial T_{r(x, t)}}{\partial x}\right)}{\partial x} d x\right)+\rho C A \frac{\partial T_{r(x, t)}}{\partial t} d x
\end{aligned}
$$

\section{B.2. Matlab code}

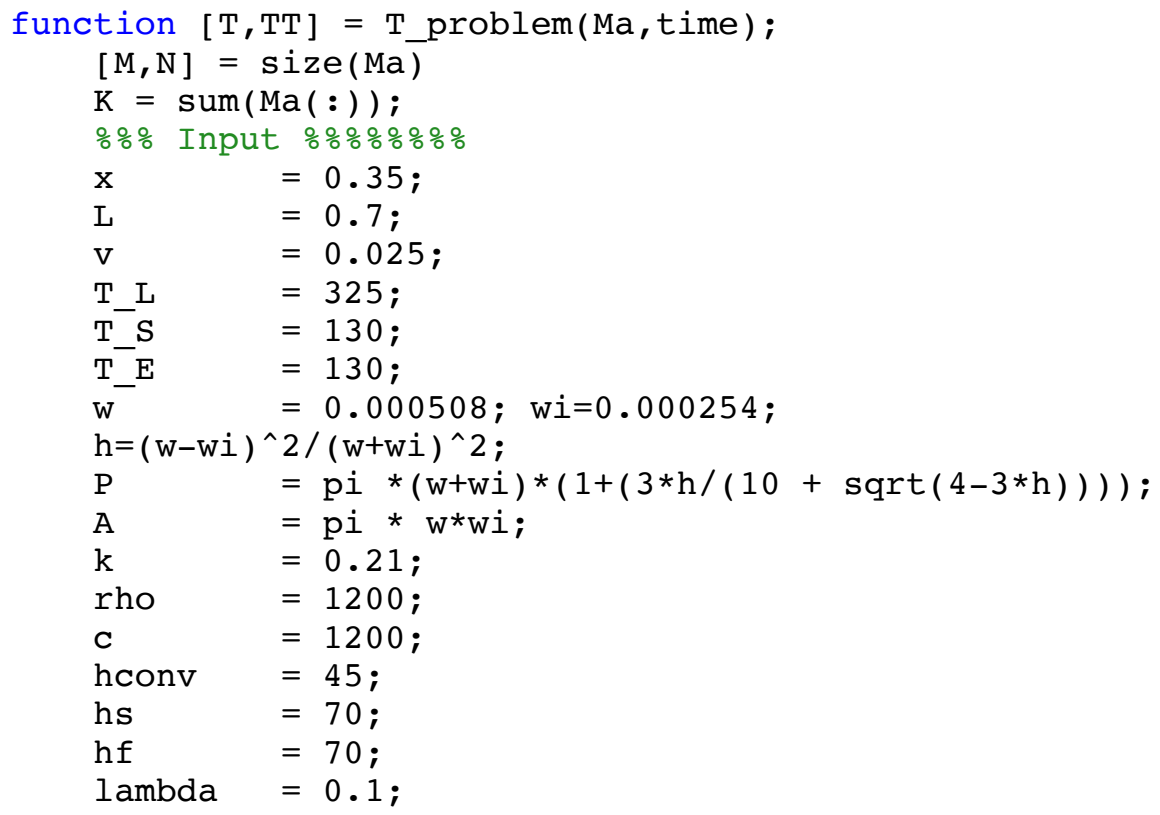




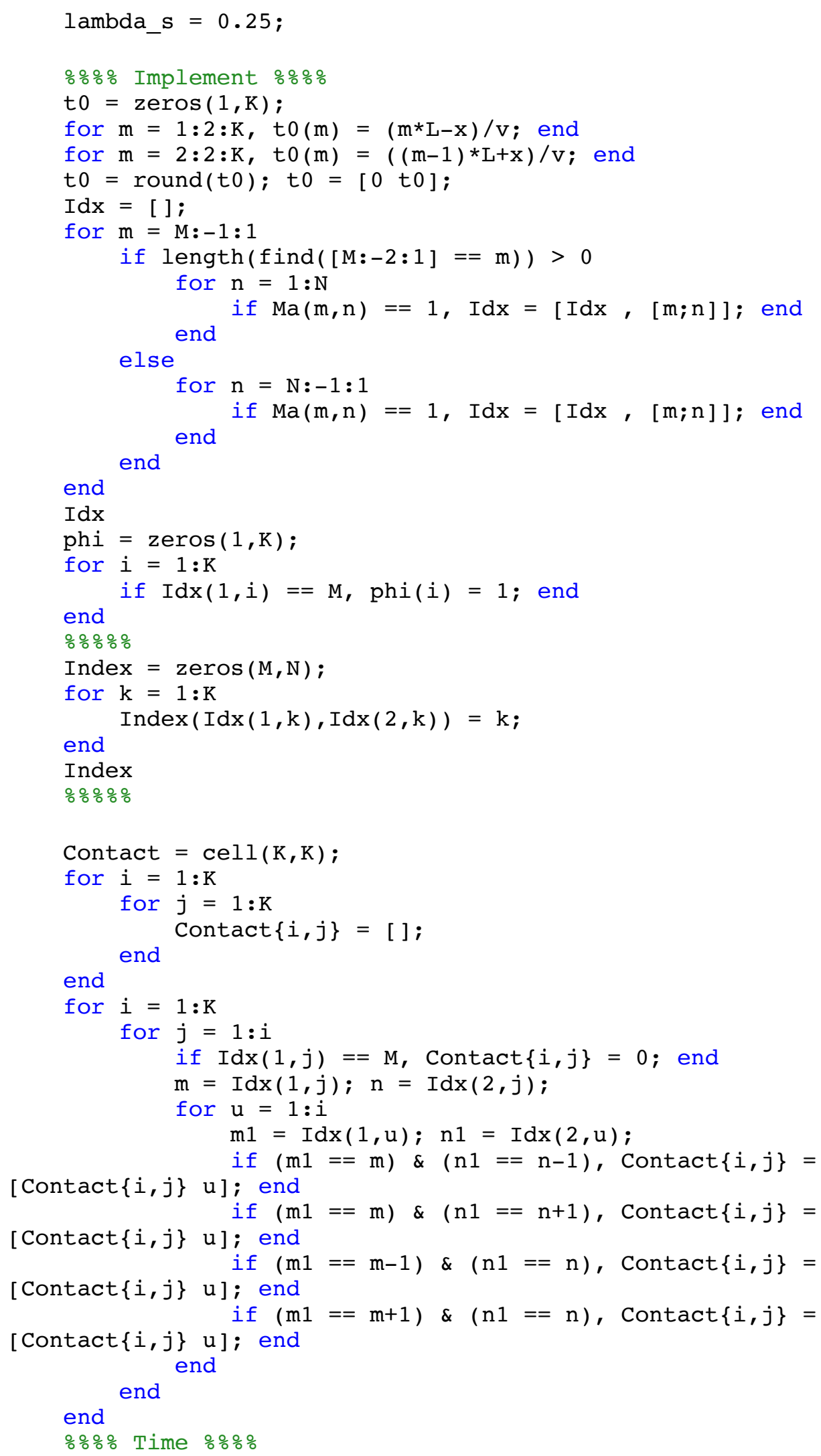




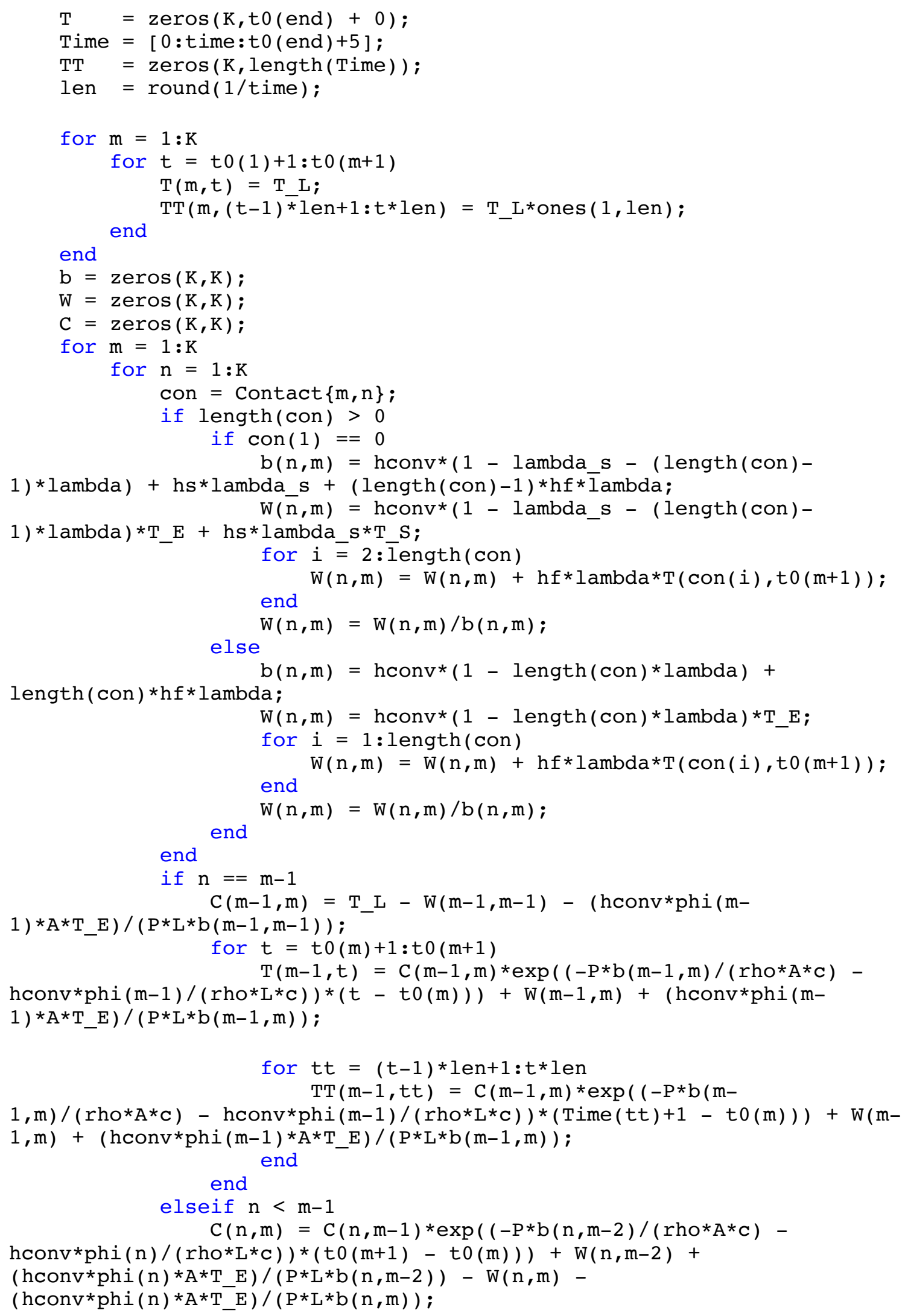




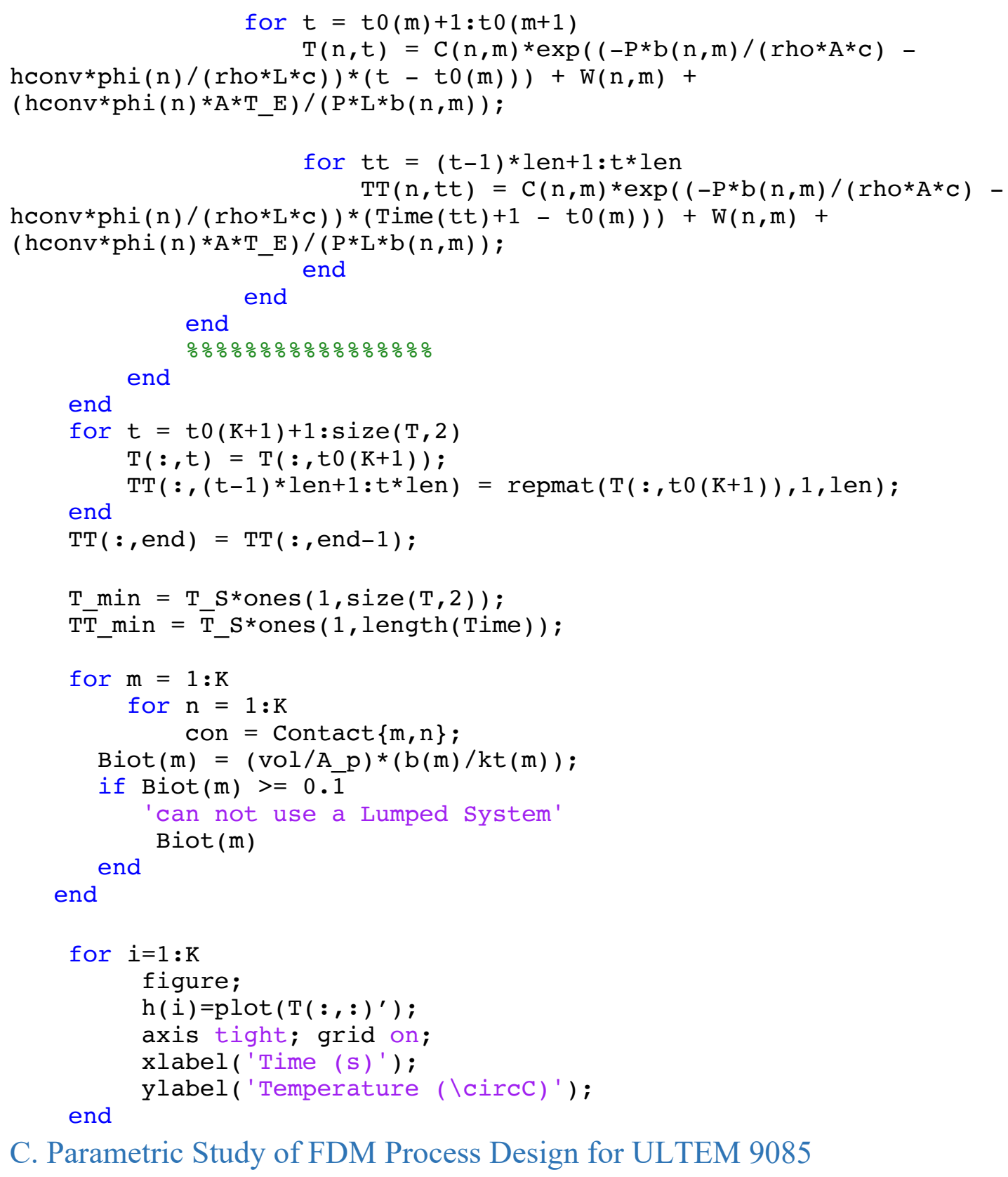

This project, sponsored by Honeywell Kansas City, was to develop a procedure which can monitor and predict the effects of the FDM process parameters on the mechanical properties of printed parts. There are no absolute guidelines for mechanical testing of 3D printing and very little work has been done in material characterization and process optimization. Therefore, optimized approaches for ULTEM (polyetherimide 
family, amorphous material) are needed in order for practical application.

The investigated factors in this project were only focused on layer thickness, raster gap, and build chamber temperature. These factors are combined as an L9, standard orthogonal array for parametric analysis for time efficiency. Mechanical properties in tensile testing associated with each design were chosen as the design performance in each of the planned experiments. Specimen design followed ASTM D3039. Each of the experiments, outlined in the given table, was performed using same build orientation, $\mathrm{XZ}$ axis (Edge). Raster angle for all filling was adjusted to $+/-45^{\circ}$. ANOVA (Analysis of Variances) method was used to estimate the percentage contribution of each parameter into mechanical properties with respect to Young's modulus, yield strength, ultimate strength, and percentage of elongation.

Tensile specimen design - ASTM D3039 [38].
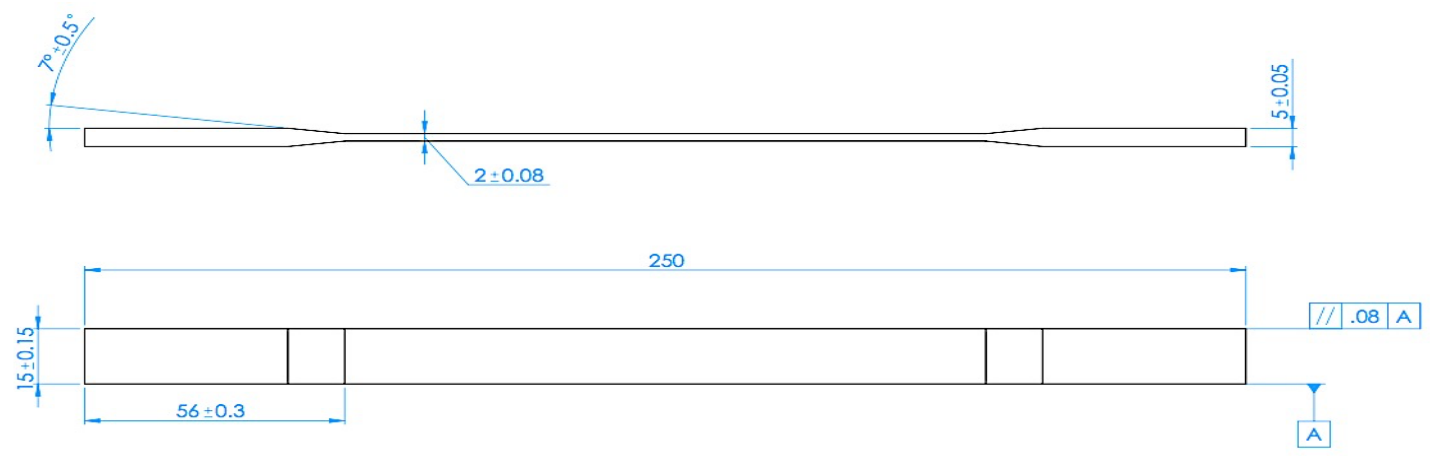

Factors and their alternative levels

\begin{tabular}{|l|c|c|c|}
\hline \multirow{2}{*}{ Factors } & \multicolumn{3}{|c|}{ Levels } \\
\cline { 2 - 4 } & 1 & 2 & 3 \\
\hline A. Layer Thickness, inches & 0.010 & 0.013 & 0.010 \\
\hline B. Raster Gap, inches & 0.000 & -0.001 & -0.002 \\
\hline C. Chamber Temperature ${ }^{\circ} \mathrm{C}$ & Normal & Low & Normal \\
\hline
\end{tabular}




\section{Build orientation and raster angle.}

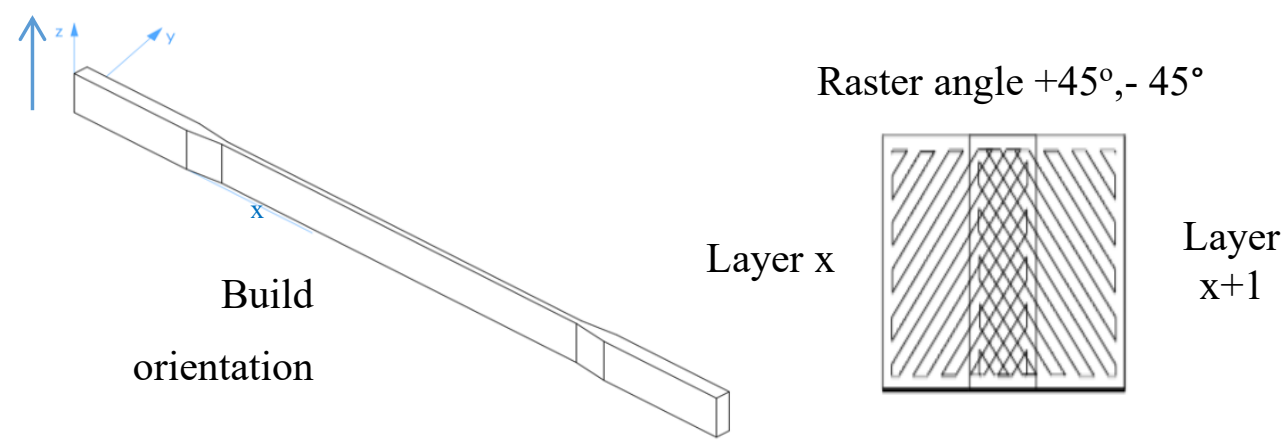

The summary in below chart shows the percentage contribution of each factor (layer thickness, raster gaps, chamber temperature) on four mechanical property responses of Ultem 9085 (Young's modulus, yield strength, ultimate strength and percent of elongation). It is obvious that the raster gap factor has the highest contribution for yield strength and young's modulus of about $50 \%$ and more than $80 \%$ for percent elongation. These results are expected because the negative gaps leads to denser layers and fewer voids of structure in general. The layer thickness factor has the intermediate contribution and can be useful for some specialized application. The chamber temperature has least contribution to the four responses. Overall, the raster gap is the most important factor to control or the properties of the printed product while chamber temperature is the least important of the three factors. 
Percentage contribution of factors on mechanical properties of Ultem 9085 printed parts.

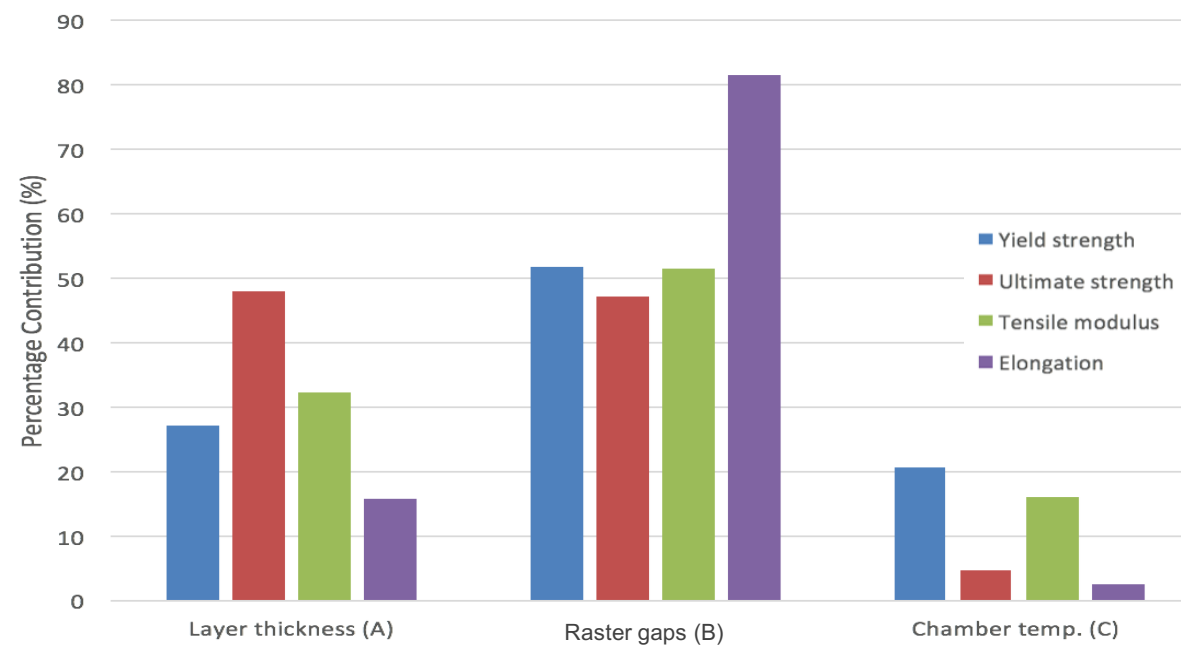

D. Tensile experiment data

\begin{tabular}{|l|l|c|c|c|}
\hline & Raster gap $(\mathrm{mm})$ & -0.0025 & 0.000 & 0.0025 \\
\hline Tensile strength & Raster angles $\left[+0^{\circ},-0^{\circ}\right]$ & 45.34 & 40.32 & 25.12 \\
$(\mathrm{MPa})$ & $(3.15)$ & $(5.92)$ & $(4.04)$ \\
\cline { 2 - 5 } $\begin{array}{l}\text { (Flat build } \\
\text { orientation) }\end{array}$ & Raster angles $\left[+45^{\circ},-45^{\circ}\right]$ & 69.60 & 51.11 & 29.45 \\
& & $(4.54)$ & $(4.09)$ & $(4.38)$ \\
\cline { 2 - 5 } & Raster angles $\left[+30^{\circ},-60^{\circ}\right]$ & 46.33 & 41.23 & 30.25 \\
Tensile strength & $(4.81)$ & $(2.89)$ & $(4.11)$ \\
$(\mathrm{MPa})$ & Raster angles $\left[+0^{\circ},-0^{\circ}\right]$ & 34.5 & 35.3 & 33.4 \\
$(\mathrm{Up} \mathrm{right} \mathrm{build}$ & Raster angles $\left[+45^{\circ},-45^{\circ}\right]$ & $3.05)$ & $(2.75)$ & $(3.05)$ \\
\cline { 2 - 5 } orientation) & & $(2.22)$ & 35.8 & 34.7 \\
\cline { 2 - 5 } & Raster angles $\left[+30^{\circ},-60^{\circ}\right]$ & 33.9 & 34.5 & 32.6 \\
& & $(4.34)$ & $(3.31)$ & $(1.15)$ \\
\hline
\end{tabular}




\section{BIBLIOGRAPHY}

[1] S. Scott Crump, Apparatus and method for creating three-dimensional objects, (1992). https://patents.google.com/patent/US5121329A/en (accessed May 3, 2019).

[2] Stratasys, Stratasys website, (n.d.). http://www.stratasys.com/corporate/about-us (accessed February 3, 2020).

[3] G.M. Shashi, M.A.R. Laskar, H. Biswas, A. Saha, A Brief Review of Additive Manufacturing with Applications, 2017.

[4] Stratasys, Stratasys materials, (n.d.). http://www.stratasys.com/materials (accessed February 3, 2020).

[5] B. Wendel, D. Rietzel, F. Kühnlein, R. Feulner, G. Hülder, E. Schmachtenberg, Additive processing of polymers, Macromol. Mater. Eng. 293 (2008) 799-809. doi:10.1002/mame.200800121.

[6] F. Awaja, M. Gilbert, G. Kelly, B. Fox, P.J. Pigram, Adhesion of polymers, Prog. Polym. Sci. 34 (2009) 948-968. doi:10.1016/j.progpolymsci.2009.04.007.

[7] 3dhubs, (n.d.). https://www.3dhubs.com/knowledge-base/introduction-fdm-3dprinting (accessed February 3, 2020).

[8] Standard Terminology for Additive Manufacturing-Coordinate Systems and Test Methodologies, (13AD).

[9] W. Wu, W. Ye, Z. Wu, P. Geng, Y. Wang, J. Zhao, Influence of layer thickness, raster angle, deformation temperature and recovery temperature on the shape- 
memory effect of 3D-printed polylactic acid samples, Materials (Basel). 10 (2017) 970.

[10] F. Rayegani, G. Onwubolu, Fused deposition modelling (FDM) process parameter prediction and optimization using group method for data handling (GMDH) and differential evolution (DE), Int. J. Adv. Manuf. Technol. 73 (2014) 509-519. doi:10.1007/s00170-014-5835-2.

[11] S.F. Costa, F.M. Duarte, J.A. Covas, Estimation of filament temperature and adhesion development in fused deposition techniques, J. Mater. Process. Technol. 245 (2017) 167-179. doi:10.1016/j.jmatprotec.2017.02.026.

[12] Q. Sun, Bond formation between polymer filaments in fused deposition modeling process, (2006).

[13] T.J. Coogan, D.O. Kazmer, Healing simulation for bond strength prediction of FDM, Rapid Prototyp. J. 23 (2017) 551-561. doi:10.1108/RPJ-03-2016-0051.

[14] Q. Sun, G.M. Rizvi, C.T. Bellehumeur, P. Gu, Experimental study of the cooling characteristics of polymer filaments in FDM and impact on the mesostructures and properties of prototypes, in: Solid Free. Fabr. Proc., 2003: pp. 313-323. https://sffsymposium.engr.utexas.edu/Manuscripts/2003/2003-29Bellehumeur.pdf\%0Ahttp://edge.rit.edu/edge/P10551/public/SFF/SFF\%5Cn2003 \%5CnProceedings/2003\%5CnSFF\%5CnPapers/29Bellehumeur.pdf\%5Cnhttp://edge.rit.edu/edge/P10551/public/SFF/SFF 2003 Proceedin. 
[15] K.C. Ang, K.F. Leong, C.K. Chua, M. Chandrasekaran, Investigation of the mechanical properties and porosity relationships in fused deposition modellingfabricated porous structures, Rapid Prototyp. J. 12 (2006) 100-105. doi:10.1108/13552540610652447.

[16] E. Ryshkewitch, Compression Strength of Porous Sintered Alumina, J. Am. Ceram. Soc. 36 (1953) 1965-1968. doi:10.1128/aem.02809-07.

[17] R.P. Wool, B. -L Yuan, O.J. McGarel, Welding of polymer interfaces, Polym. Eng. Sci. 29 (1989) 1340-1367. doi:10.1002/pen.760291906.

[18] O.A. Mohamed, S.H. Masood, J.L. Bhowmik, Analytical modelling and optimization of the temperature-dependent dynamic mechanical properties of fused deposition fabricated parts made of PC-ABS, Materials (Basel). 9 (2016) 895. doi:10.3390/ma9110895.

[19] H. Xia, J. Lu, S. Dabiri, G. Tryggvason, Fully resolved numerical simulations of fused deposition modeling. Part I: fluid flow, Rapid Prototyp. J. 24 (2018) 463-476. doi:10.1108/RPJ-12-2016-0217.

[20] H. Xia, J. Lu, G. Tryggvason, Fully resolved numerical simulations of fused deposition modeling. Part II - solidification, residual stresses and modeling of the nozzle, Rapid Prototyp. J. 24 (2018) 973-987. doi:10.1108/RPJ-11-2017-0233.

[21] O.A. Mohamed, S.H. Masood, J.L. Bhowmik, Optimization of fused deposition modeling process parameters: a review of current research and future prospects, Adv. Manuf. 3 (2015) 42-53. doi:10.1007/s40436-014-0097-7. 
[22] H. Bikas, P. Stavropoulos, G. Chryssolouris, Additive manufacturing methods and modelling approaches: a critical review, Int. J. Adv. Manuf. Technol. 83 (2016) $389-405$.

[23] A. Qattawi, M.A. Ablat, Design consideration for additive manufacturing: fused deposition modelling, Open J. Appl. Sci. 7 (2017) 291.

[24] C.-T. Su, Quality engineering: off-line methods and applications, CRC press, 2013.

[25] S. Rohde, J. Cantrell, A. Jerez, C. Kroese, D. Damiani, R. Gurnani, L. DiSandro, J. Anton, A. Young, D. Steinbach, P. Ifju, Experimental Characterization of the Shear Properties of 3D-Printed ABS and Polycarbonate Parts, in: S. Yoshida, L. Lamberti, C. Sciammarella (Eds.), Exp. Mech., Springer International Publishing, Cham, 2018: pp. 871-884. doi:10.1007/s11340-017-0343-6.

[26] M.S. Uddin, M.F.R. Sidek, M.A. Faizal, R. Ghomashchi, A. Pramanik, Evaluating Mechanical Properties and Failure Mechanisms of Fused Deposition Modeling Acrylonitrile Butadiene Styrene Parts, J. Manuf. Sci. Eng. 139 (2017) 081018. doi:10.1115/1.4036713.

[27] J. Torres, M. Cole, A. Owji, Z. DeMastry, A.P. Gordon, An approach for mechanical property optimization of fused deposition modeling with polylactic acid via design of experiments, Rapid Prototyp. J. 22 (2016) 387-404.

[28] C.A. Griffiths, J. Howarth, G. de-A. Rowbotham, A. Rees, Effect of build parameters on processing efficiency and material performance in fused deposition modelling, Procedia CIRP. 49 (2016) 28-32. 
[29] Y. Cicek, A. Altinkaynak, E. Balta, Numerical and experimental analysis of infill rate on the mechanical properties of fused deposition modelling polylactic acid parts, Proc. SPE ANTEC ${ }^{\circledR}$ Anaheim. (2017).

[30] P. Kulkarni, D. Dutta, Deposition Strategies and Resulting Part Stiffnesses in Fused Deposition Modeling, J. Manuf. Sci. Eng. 121 (1999) 93. doi:10.1115/1.2830582.

[31] A.S. El-Gizawy, S. Corl, B. Graybill, Process-induced Properties of FDM Products, in: ICMET, Int. Conf. Mech. Eng. Technol. Congr. Expo., 2011: p. 7. http://usglobalimages.stratasys.com/Main/Files/FDM Test Reports/Processinduced Properties of FDM Products.pdf?v=634600741947138884.

[32] A.S. El-Gizawy, Characterization of Anisotropic Properties of Fused Deposition Modeling Polycarbonate Components, in: First Int. Conf. Adv. Mater. Appl. Acoust. Vib. Cent. Adv. Mater. Br. Univ. Egypt, Cairo, Egypt, 2009.

[33] S.H. Ahn, C. Baek, S. Lee, I.S. Ahn, Anisotropic tensile failure model of rapid prototyping parts - Fused Deposition Modeling (FDM), Int. J. Mod. Phys. B. 17 (2003) 1510-1516. doi:10.1142/S0217979203019241.

[34] B.N. Panda, K. Shankhwar, A. Garg, Z. Jian, Performance evaluation of warping characteristic of fused deposition modelling process, Int. J. Adv. Manuf. Technol. 88 (2017) 1799-1811.

[35] J.W. Zhang, A.H. Peng, Process-parameter optimization for fused deposition modeling based on Taguchi method, in: Adv. Mater. Res., Trans Tech Publ, 2012: pp. $444-447$. 
[36] T.-M. Wang, J.-T. Xi, Y. Jin, A model research for prototype warp deformation in the FDM process, Int. J. Adv. Manuf. Technol. 33 (2007) 1087-1096.

[37] M. Vatani, F. Barazandeh, A. Rahimi, A. Sanati Nezhad, Distortion modeling of SL parts by classical lamination theory, Rapid Prototyp. J. 18 (2012) 188-193.

[38] J. Yu, X. Lin, L. Ma, J. Wang, X. Fu, J. Chen, W. Huang, Influence of laser deposition patterns on part distortion, interior quality and mechanical properties by laser solid forming (LSF), Mater. Sci. Eng. A. 528 (2011) 1094-1104.

[39] L. Xinhua, L. Shengpeng, L. Zhou, Z. Xianhua, C. Xiaohu, W. Zhongbin, An investigation on distortion of PLA thin-plate part in the FDM process, Int. J. Adv. Manuf. Technol. 79 (2015) 1117-1126.

[40] C. Baojuan, L. Yande, H. Fuben, Factor Analysis and Optimization of Warpage Deformation in FDM [J], Electromachining Mould. 4 (2012).

[41] B. Brenken, E. Barocio, A. Favaloro, V. Kunc, R.B. Pipes, Fused filament fabrication of fiber-reinforced polymers: A review, Addit. Manuf. (2018).

[42] T.A. Osswald, G. Menges, Materials science of polymers for engineers, Carl Hanser Verlag GmbH Co KG, 2012.

[43] D. Espalin, J. Alberto Ramirez, F. Medina, W.M. Johnson, M. Rowell, B. Deason, M. Eubanks, B.N. Turner, R. Strong, S.A. Gold, A review of melt extrusion additive manufacturing processes: I. Process design and modeling, Rapid Prototyp. J. Rapid Prototyp. J. Rapid Prototyp. J. Iss Rapid Prototyp. J. 20 (2014) 192-204. doi:10.1108/RPJ-01-2013-0012. 
[44] S.F. Costa, F.M. Duarte, J.A. Covas, Thermal conditions affecting heat transfer in FDM/FFE: a contribution towards the numerical modelling of the process: This paper investigates convection, conduction and radiation phenomena in the filament deposition process, Virtual Phys. Prototyp. 10 (2015) 35-46.

[45] P.K. Gurrala, S.P. Regalla, Part strength evolution with bonding between filaments in fused deposition modelling: This paper studies how coalescence of filaments contributes to the strength of final FDM part, Virtual Phys. Prototyp. 9 (2014) 141149.

[46] O. Pokluda, C.T. Bellehumeur, J. Vlachopoulos, Modification of Frenkel's model for sintering, AIChE J. 43 (1997) 3253-3256. doi:10.1002/aic.690431213.

[47] Q.H. Nguyen, Development of predictive models for the coalescence of fused deposition modeling fibers, University of Missouri- Columbia, 2017.

[48] B. Gebhart, Heat conduction and mass diffusion, McGraw-Hill, 1993.

[49] R. Klein, Laser Polymer Welding, Laser Technol. Appl. Adhes. Relat. Areas. (2018) 211.

[50] G. Wypych, Handbook of Polymers, Elsevier, 2016. doi:10.1093/oxfordhb/9780199663170.001.0001.

[51] M.C. Shen, A. Eisenberg, Glass transitions in polymers, Prog. Solid State Chem. 3 (1967) 407-481. 


\section{VITA}

Thao T.P. Phan was born in Thai Nguyen, Vietnam, on June 21, 1989. Thao attended the elementary schools and high school in Thai Nguyen in May 2007. The following August Thao entered Thai Nguyen University of Technology and in March 2013 received the degree of Bachelor in Mechanical Engineering with honor. Thao entered University of Missouri- Columbia, USA in August 2015, received a Master of Engineering in Mechanical Engineering in May 2018 and received a Ph.D. in Mechanical Engineering in December 2020. 